IZA DP No. 8576

Understanding the Role of Immigrants' Legal Status:

Evidence from Policy Experiments

Francesco Fasani

October 2014 


\title{
Understanding the Role of Immigrants' Legal Status: Evidence from Policy Experiments
}

\author{
Francesco Fasani \\ Queen Mary University of London, \\ CReAM and IZA
}

\section{Discussion Paper No. 8576 October 2014}

\author{
IZA \\ P.O. Box 7240 \\ 53072 Bonn \\ Germany \\ Phone: +49-228-3894-0 \\ Fax: +49-228-3894-180 \\ E-mail: iza@iza.org
}

\begin{abstract}
Any opinions expressed here are those of the author(s) and not those of IZA. Research published in this series may include views on policy, but the institute itself takes no institutional policy positions. The IZA research network is committed to the IZA Guiding Principles of Research Integrity.

The Institute for the Study of Labor (IZA) in Bonn is a local and virtual international research center and a place of communication between science, politics and business. IZA is an independent nonprofit organization supported by Deutsche Post Foundation. The center is associated with the University of Bonn and offers a stimulating research environment through its international network, workshops and conferences, data service, project support, research visits and doctoral program. IZA engages in (i) original and internationally competitive research in all fields of labor economics, (ii) development of policy concepts, and (iii) dissemination of research results and concepts to the interested public.
\end{abstract}

IZA Discussion Papers often represent preliminary work and are circulated to encourage discussion. Citation of such a paper should account for its provisional character. A revised version may be available directly from the author. 


\section{ABSTRACT \\ Understanding the Role of Immigrants' Legal Status: Evidence from Policy Experiments}

Programs aimed at reducing the presence of unauthorised immigrants are often at the core of the migration policy debate in host countries. In recent years, a growing body of empirical literature has attempted to understand the effect of lacking legal status on immigrants' outcomes and behaviour. The main difficulties in this field are the scarcity of data and the identification challenge posed by endogenous selection into legal status. The vast majority of these articles have therefore used amnesty programs (or similar policy changes) to establish causal relationships. In this paper, we propose a first systematic review of the empirical literature for the US and Europe on the impact of legal status on different immigrants' outcomes. We then present some new evidence of the relationship between labour market outcomes and legal status in the Italian context. In our empirical analysis, we first provide some descriptive evidence on differences in the outcomes for groups with different residence statuses, and we then exploit a specific amnesty programme to produce causal estimates of the impact of legal status. Our results confirm previous findings in the literature and show that the design of the specific amnesty analysed matters in shaping its effects.

JEL Classification: F22, J61, K37

Keywords: $\quad$ illegal migration, amnesty, migration policy

Corresponding author:

Francesco Fasani

Queen Mary University of London

School of Economics and Finance

327 Mile End Road

E1 4 NS London

United Kingdom

E-mail: f.fasani@qmul.ac.uk

\footnotetext{
* I am especially grateful to Carlo Devillanova and Tommaso Frattini for many useful discussions and to Gian Carlo Blangiardo for providing the ISMU survey data. The usual disclaimer applies.
} 


\section{Introduction}

An estimated population of 11.5 million undocumented immigrants that currently reside in the US (Hoefer et al. (2012)) waits to learn what their futures will be. Are they bound to become legal permanent residents - or even citizens - in the US, or are they doomed to remain "in the shadows" of American society for years to come? Proponents of general amnesty stress the urgency of recognising the contribution provided by this population to the US economy and society: becoming full members of the US nation would allow these immigrants to enjoy the benefits (civil rights, access to the welfare state, etc.) and to bear the costs (mainly through taxation) of that membership. In the views of those that oppose amnesty, instead, such a policy would reward law-breaking behaviour, reveal the intertemporal inconsistency of the US migration policy and attract even larger inflows of undocumented immigrants in the future. A heated debate on the opportunity to establish general amnesty has continued for years in the US Congress and Senate, and it seems to remain far from a final settlement. It is indeed a politically difficult decision to make. The quality of life of millions of immigrants (and of their families abroad) is at stake, but political stances on how unauthorised immigrants should be considered - and thus treated - diverge widely.

All sides in this debate, however, share a fairly limited knowledge of the consequences of lacking legal status for immigrants' outcomes and behaviour and a relatively narrow understanding of the possible impact of general amnesty for legalised immigrants and the rest of the population. Indeed, as we discuss in this paper, this is an area in which economic research has only recently started to provide answers and in which many important aspects remain completely unexplored. For instance, there is a great deal of descriptive evidence that compares labour market outcomes of documented and undocumented immigrants, generally showing that the latter are more disadvantaged than the former. What really matters for policy, though, is understanding to what extent these observed differentials are due to a causal effect of legal status or rather to the differences in the process of self-selection into legal status. Indeed, only 
a causal parameter would tell us what changes we can reasonably expect to observe by granting general amnesty or by offering some alternative pathway to legalisation to undocumented immigrants. Furthermore, legal residence status may produce effects beyond the labour market and affect, for instance, criminal behaviour, consumption and remitting decisions or the health status of immigrants: these dimensions have high political relevance but have received little attention from researchers to date. The policy and academic debate also needs to focus more on the fact that there are many alternative ways to grant legal status to immigrants. Existing research has completely overlooked the role played by alternative designs of legalisation programs in shaping the effects produced by legal status (see Devillanova et al. (2014) for an exception). Moreover, the literature still needs to fully understand how general equilibrium effects generated by one-time mass legalisation programs may alter the overall impact of granting legal status with respect to schemes that, for instance, permanently allow individuals who meet specific requirements to become legal residents.

The paper has the following structure. Section 2 describes the theoretical framework, summarising all mechanisms linking legal status and immigrants' outcomes that have been proposed in the literature - and discuss the empirical challenges this literature faces. In section 3, we review the existing empirical literature for the US and Europe on the impact of legal status on labour market outcomes (3.1), immigrants' crime (3.2) and other outcomes such as remittances and consumption (3.3). In section 4, we present some new evidence on the relationship between labour market outcomes and legal status in the Italian context: we first provide some descriptive evidence on differences in outcomes for groups with different residence statuses, and we then exploit a specific amnesty programme to produce arguably causal estimates. We describe the institutional setting and the amnesty in section 4.1, while data and descriptive statistics are discussed in section 4.2. In section 4.3, we explain our empirical strategy and we present and interpret our estimation results in section 4.4. Some concluding remarks are included in the final section 5 . 


\section{Theoretical Framework and Empirical Challenges}

Why should we expect legal status to matter to immigrants? Most of the discussion on potential channels in the literature has centred around labour market outcomes. Several mechanisms have been discussed, and we summarise them here in no particular order.

First, unauthorised immigrants are often constrained to certain segments of the labour market in which their illegal status is easily hidden or ignored. Legalisation may thus provide them with increased labour market mobility, expanding their opportunities for employment into occupations and sectors that were unaccessible to them as undocumented immigrants (Kossoudji \& Cobb-Clark (2000)). As a consequence, immigrants should find better job matches that pay higher returns for their qualifications, skills and working experience (Bratsberg et al. (2002)). ${ }^{1}$ Second, legal status generally provides access to welfare provisions, unemployment benefit schemes and public assistance programs, improving immigrants' outside options in the labour market. The consequent increase in their reservation wages will potentially reduce their labour supply and allow them to spend more time in unemployment while looking for better employment opportunities. From the point of view of employers, the cost of employing legalised immigrants increases if eluding payroll taxes and social security contributions becomes more difficult. Third, when gaining legal status, immigrants cease being exposed to the hazard of migration authorities enforcement. The fear of being arrested and deported may make it difficult and risky to search for alternative wage offers, inducing undocumented immigrants to lower their reservation wages and accept the first available offer. The risk of enforcement makes job matches with undocumented immigrants inherently unstable, reducing their value and the incentives to invest in training for both employees and employers. Moreover, wages offered to undocumented immigrants will be discounted by the expected fine employers may have to pay if these employers are caught employing undocumented workers. Fourth, the three previous mechanisms imply that obtaining legal status increases immigrants' bargaining power

\footnotetext{
${ }^{1}$ Accetturo \& Infante (2010), for instance, show that the returns to schooling for undocumented immigrants in Italy are about half of those for documented immigrants.
} 
- given that they enjoy higher occupational mobility, better outside options and no fear of being deported - and reduces the scope for employers to exert monopsonistic power in setting wages and working conditions (Rivera-Batiz (1999), Hotchkiss \& Quispe-Agnoli (2009)).

From all previous channels, we would expect legal status to unequivocally increase wages and returns to skills for employed immigrants. The effect on employment is, instead, theoretically undetermined because the effects on both labour demand and labour supply are ambiguous. On the demand side, matches with documented immigrants are more stable and do not imply the risk of fines, making them potentially more valuable for employers. Nevertheless, these matches may also imply higher costs if payroll taxes have to be paid and workers have more bargaining power in demanding higher salaries. The overall impact on the labour supply will instead depend on the relative size of the income and substitution effects induced by the higher wages associated with legal status. ${ }^{2}$ As we will extensively discuss in section 3 , empirical results in the literature on legal status tend to find increases in wages (although with large heterogeneity in the size of the effect) and an ambiguous impact on employment after legalisation.

The variety of the potential channels at work and the ambiguity of some of the theoretical conclusions imply that empirical work is needed to establish the size and the sign of the causal impact of changes of legal status on immigrants' outcomes. Unfortunately, researchers face two major limitations to performing this task. The scarcity of data is obviously the first limitation. Ideally, one would need to interview representative samples of undocumented immigrants, follow them over time and compare before- and after-legalisation outcomes, and have suitable comparison groups of undocumented immigrants randomly excluded from the access to legal status. Unfortunately, the unrecorded nature of undocumented immigration makes data collection a very difficult task to accomplish. As we will see in our literature review (see section 3), few datasets on undocumented immigrants are available to researchers, and all of them suffer from some serious shortcomings.

\footnotetext{
${ }^{2}$ See Devillanova et al. (2014) for a thorough discussion of the labour demand and supply effects of legal status.
} 
Even when some data are available, the researcher must address the second major challenge in this literature: unless the endogenous selection into legal status is effectively addressed, a cross-sectional comparison of immigrants with different residence statuses is not necessarily informative about causal relationships. As a matter of fact, any observed differential between documented and undocumented immigrants could be due to differences in either observable characteristics, the returns to those characteristics, or unobserved characteristics related to the selection into legal status. Even having longitudinal data on individuals that change their legal status over time does not necessarily reduce our concerns about selection, unless those changes were exogenously determined. Indeed, it is difficult to determine whether any observed adjustment following legalisation is fully due to the change in visa status or rather to some unobserved individual characteristics. Individuals that are more likely to benefit from legalisation, for instance, are also more likely to make efforts to obtain legal resident status. Similarly, more motivated immigrants are more likely to perform well in the job market and are also more likely to make efforts to adjust their visa status. The selection into legal status is a repeated and continuous process: not only do immigrants make their initial choice regarding the channel of entry (legal vs. illegal) in the host country but, once there, they also keep making new endogenous decisions regarding their residence status (e.g., to apply for amnesty, renew their residence permits, return home after failing to be legalised, etc.). As we discuss in section 3, the existing literature has generally exploited legalisation programs - or similar policies in the host country - in order to find sources of exogenous variation in immigrants' legal status.

\section{Empirical Evidence on Legal Status}

In this section, we review the existing empirical literature for the US and Europe on the impact of legal status on labour market outcomes (3.1), immigrants' crime (3.2) and other outcomes (remittances, consumption, health, etc.) (3.3). 


\subsection{Documented and undocumented immigrants in the labour mar- ket}

The 1986 IRCA in the US

The majority of papers that analyse the impact of legal status on immigrants' outcomes has focused on a major policy experiment, the Legally Authorised Workers (LAW) programme, one of the two legalisation programs introduced in the US by the 1986 Immigration Reform and Control Act (IRCA). ${ }^{3}$ This programme offered permanent legal status to all immigrants who resided in the US since the 1st of January 1982. The process of legalisation lasted approximately two years - more than 95 per cent of legalisations took place between 1989 and 1991 and eventually legalised more than 1.6 million immigrants. Studies analysing the LAW-IRCA amnesty generally use data from the Legalised Population Survey (LPS), a longitudinal survey of immigrants who obtained legal status through that particular programme. In 1989, the LPS interviewed a random sample of 6.2 thousand applicants for the LAW-IRCA programme , collecting an extensive set of retrospective information relating to their labour market and general socioeconomic experience both at at the time they first entered in the US and the moment of applying for amnesty (in 1986-87). A second wave of the survey was conducted in 1992, interviewing only about four thousand legalised applicants from the original sample. The LPS sample is representative of all undocumented immigrants in the United States who decided to apply for the IRCA programme and had the necessary documentation to seek legalisation. These data allow researchers to study the changes in outcomes before and after legalisation, but given that all individuals in the sample were legalised, an (arbitrary) choice of a control group is needed in order to be able to implement a difference-in-differences approach.

Rivera-Batiz (1999) analyses the differences in earnings between legal and illegal Mexican

\footnotetext{
${ }^{3}$ The IRCA included a second legalisation programme the Special Agricultural Worker (SAW) programme that conditioned eligibility on having been employed in the agricultural sector for a minimum amount of time in previous years. Having legalised over 1.2 million unauthorised immigrants, the SAW-IRCA programme had a similar magnitude to the LAW-IRCA programme. Nevertheless, the SAW programme has been almost completely overlooked by the literature. See Sampaio et al. (2013) for an exception.
} 
immigrants in the US, and it is one of the first studies to use LPS data. ${ }^{4}$ He first compares a cross-section of LPS respondents and legal Mexican immigrants from the 1990 US Population Census, showing that the latter earn approximately 40 per cent more than the former. Using a Blinder-Oaxaca decomposition, he shows that less than half of this wage gap is explained by differences in observable characteristics between the two groups, suggesting that legal status may account for the remaining difference. Furthermore, he analyses the wage growth experienced by legalised immigrants in the LPS sample. He finds that changes in the characteristics of immigrants over time (in particular, in terms of English proficiency, education and the duration of residence in the US) can only partially explain the observed increased in their wages after legalisation, pointing to the change in legal status as a major determinant of such an improvement.

Kossoudji \& Cobb-Clark (2000) examine the occupational concentration and mobility of unauthorised Mexican immigrants legalised under IRCA. Using LPS data, the authors obtain information on immigrants' occupations at three points in time: when they first entered the US, when they applied for amnesty (1986-1987) and after legalisation (1992). They find that unauthorised immigrants have high occupational mobility: almost three-quarters of the individuals in their sample changed occupations both before and after legalisation. They show that while pre-legalisation mobility is primarily driven by English language ability and job characteristics, post-legalisation mobility seems to be almost exclusively due to legalisation itself. Kossoudji \& Cobb-Clark (2000) conclude that legal status creates a whole new set of opportunities that allow newly legalised workers to move up the occupational ladder.

Kossoudji \& Cobb-Clark (2002) aim to assess whether the observed increase in earnings following legalisation observed in previous studies (as in Rivera-Batiz (1999)) are the result of the change in legal status or rather due to fluctuations in the US labour market conditions that affected workers in the sample. For this purpose, they use LPS data together with a panel of

\footnotetext{
${ }^{4}$ Previous studies on labour market outcomes of unauthorised immigrants had relied on small and unrepresentative samples of undocumented immigrants, such as apprehended immigrants or those who returned to Mexico. See, among others, Chiswick (1988) and Massey (1987).
} 
Latino men from the National Longitudinal Survey of Youth (NLSY), which serves as comparison group. Although they do not explicitly adopt a difference-in-differences approach, they run separate wage regressions for the two groups of immigrants and find that wage determinants are structurally different after amnesty for legalised men but not for the comparison group measured during the same time periods. According to their calculations, the wage penalty for being unauthorised ranges from $14 \%$ to $24 \%$, while the wage benefit of legalisation under IRCA was approximately $6 \%$.

Amuedo-Dorantes et al. (2007) adopt a quasi-experimental design that closely follows Kossoudji \& Cobb-Clark (2002) in constructing treatment and control groups. They innovate with respect to that study by producing difference-in-differences estimates for both wages and employment and by analysing gender differentials in the amnesty programme effect. Their results for earnings confirm previous findings in this literature: in the 1987-1992 period, legalised immigrants experienced a substantial wage growth (9 per cent for males and 21 per cent for females). The employment rate, instead, seems to have dropped after legalisation by 5 percentage points for men and by approximately 7 percentage points for women. The authors rationalise this latter finding on employment by suggesting that the higher returns to skills and the eligibility for unemployment insurance implied by the legalisation may raise the reservation wage of skilled workers, who may choose to search longer for better job matches. Moreover, legalised women may be induced to leave the workforce if their household income has increased due to the legalisation of their partners.

Few papers study the impact of the IRCA amnesty programme using data other than LPS data. Borjas \& Tienda (1993) use an administrative file containing the individual records of amnesty applicants (Legalisation Application Processing System - LAPS) and draw comparisons with a sample of the foreign-born population from the Current Population Surveys. Although the absence of the information on applicants' educational attainment in the LAPS dataset severely weakens their analysis, the authors find that legal immigrants earn 30 per cent more 
than their undocumented counterparts.

Three very recent papers (Barcellos (2010), Lozano \& Sorensen (2011) and Pan (2012)) use large, nationally representative samples of the US population to estimate the effects of the IRCA legalisation. Although similar datasets are generally preferable to a small survey that only samples amnesty applicants (such as the LPS), they have the important drawback of not recording the legal status of immigrants. These three papers devise different approaches to exploiting the same discontinuity in legal status eligibility based on date of arrival that the LAW-IRCA programme created by asking applicants to prove their continuous residence in the US since the 1st of January 1982.

Both Pan (2012) and Barcellos (2010) use a regression discontinuity approach to compare immigrants who arrived before and after the cutoff year of 1982. Although their actual residence status is not observed, immigrants in the former cohort should have a higher probability of being legal than those in the latter cohort. Under the identifying assumption that these two cohorts of immigrants do not differ in observable and unobservable characteristics, one can claim that any estimated sharp difference in outcomes between the two groups can be interpreted as a causal effect of the policy. Pan (2012) focuses on Latino immigrants in California using data from the 1990 census and investigates gender heterogeneity in the legalisation effect. She finds that those that arrived before 1982 outperform those that arrived after 1982 in terms of male wages (4.5 per cent higher wages) and female employment probability (four percentage points difference). When looking at the long-term effect of legal status by using the 2000 census, she fails to find any significant effect between the two cohorts of immigrants. Adopting a similar empirical strategy, Barcellos (2010) analyse a nationwide sample of the US Census, Current Population Survey and American Community Survey. According to her estimates, legalisation increased the naturalisation rate of Mexican high school dropouts by 30 per cent. The impact on labour market outcomes is, instead, very limited: she finds a significant increase of 2-3 per cent in wages and non-significant effects on occupation quality and geographical mobility. ${ }^{5}$

\footnotetext{
${ }^{5}$ The identification strategies in both Pan (2012) and Barcellos (2010) suffer from similar limitations. First,
} 
Lozano \& Sorensen (2011) adopt an alternative approach to exploit the discontinuity in IRCA eligibility. They combine information from US Census data and the Mexican Migration Project (MMP): given that legal status is observed in the latter survey, they first use MMP data to estimate the probability of lacking legal status on demographic variables that are also observed in the Census. The parameters they estimate are then used to predict the likelihood that an individual observed in the US Census is undocumented. Finally, they exploit the 1982 cutoff in IRCA eligibility to develop a difference-in-differences approach where they compare the (predicted) undocumented immigrants who arrived in the US before and after 1982 with either the (predicted) undocumented immigrants who arrived before and after a placebo threshold in 1992 or with the (predicted) documented immigrants who arrived before and after 1982. They estimate that the IRCA amnesty implied a substantial increase (20 log points) in the labour market earnings of Mexican immigrants. Their estimates suggest that this gain can be primarily explained by increased occupational mobility.

\section{Other legalisation programs in the US}

The IRCA legalisation programs were not the only amnesties offered in the US in the last several decades. The 1997 Nicaraguan Adjustment and Central American Relief Act (NACARA) granted legal status to approximately 450,000 immigrants from Nicaragua, Cuba, Guatemala, and El Salvador. Kaushal (2006) investigates its labour market effects: using data from the Current Population Survey and a difference-in-differences approach, she compares immigrants from eligible countries with immigrants from other comparable Latin American countries. She finds that NACARA had a modest negative (but insignificant) effect on the employment of

their approach tends to underestimate the effect of legalisation because an unknown share of the immigrants in their "treatment" group (those who arrived before the cutoff year) were already legal before the IRCA amnesty. Second, in the datasets they use, the year of arrival is coded in groups of two to five years, preventing them from comparing individuals in a truly small neighborhood of the eligibility threshold date (threatening the credibility of the identifying assumption in their regression discontinuity design). Third, the US entered in a severe recession in 1980, with the unemployment rate peaking in 1982-83. This implies that one could expect the control group (i.e., the cohort of immigrants that arrived in the US in 1982 and after) to perform worse than those that arrived before 1982, irrespectively of the IRCA amnesty, leading to an exaggeration of the legalisation effect. 
legalised immigrants, but it raised their real wage by 3 per cent and their weekly earnings by 4 per cent. She also shows that the return to legal status is heterogenous across education groups: according to his estimates, NACARA raised the wage of the target group without a high school degree by a statistically insignificant 1 per cent and of those with high school or higher education by a statistically significant 5 per cent.

Orrenius et al. (2012) analyse the 1992 Chinese Student Protection Act (CSPA), which, in order to prevent the political persecution of participants in the Tiananmen square protests of 1989, offered permanent resident status to all Chinese nationals who had arrived in the United States before April 11, 1990. Approximately 53,000 immigrants ultimately received green cards under the CSPA. The study uses 1990 and 2000 census data to examine employment and earnings among Chinese immigrants who were likely beneficiaries of the policy. The authors use a difference-in-differences setting in which the control group is composed of immigrants from Asian countries not covered by the amnesty (Hong Kong, Taiwan, and South Korea). They find that highly-educated immigrants from mainland China experienced significant employment and earnings gains during the 1990s with respect to the other group of immigrants. Furthermore, they compare Chinese immigrants who arrived in the U.S in time to benefit from the programme with Chinese immigrants who arrived after and find that the former group had higher relative earnings in 2000 than the latter.

Rather than studying an amnesty programme, Lofstrom et al. (2013) look at the labour market outcomes of immigrants who gain legal permanent resident (LPR) status in the US (mostly through their close family ties to US citizens or to immigrants who are already LPRs). They use data from the New Immigrant Survey - a nationally representative multi-cohort longitudinal study of new legal immigrants and their children - and distinguish between immigrants who, prior to becoming LPRs, were undocumented from those who already had legal (although temporary) residence status. Their empirical approach relies on a comparison of occupational mobility and wages between these two groups of immigrants (but they do not explicitly address the endogenous selection of immigrants in one group or the other). Similarly to Kaushal (2006) 
and Orrenius et al. (2012), they find evidence of improved labour market outcomes attributable to legal status only for highly skilled workers.

\section{Amnesties in Europe}

Although amnesties are relatively frequent events in European countries - Casarico et al. (2012) count 18 amnesties granted in the EU-15 area in the 1980-2008 period - almost no empirical research has been developed to assess their labour market effects. The only exception is some recent work by Devillanova et al. (2014) that estimates the impact on employment probability of undocumented immigrants of a large general amnesty granted in Italy in 2002 . Their paper departs from the US literature in analysing, for the first time, the effects of an amnesty that conditioned eligibility both on a minimum residence requirement (similar to all of the legalisation programs studied in the US context) and on being employed at the moment of the application. Furthermore, the authors argue that amnesty eligibility status per se may generate important labour market consequences for undocumented immigrants even before legalisation takes place. Indeed, they estimate the effect of being offered legal status (i.e., the transition from being an undocumented immigrant to becoming an amnesty applicant) rather than the effect of actually gaining legal status (i.e., the transition from applicant status to legal immigrant) that has been the focus of previous studies. In their empirical strategy, they exploit the discontinuity in the predetermined arrival requirement - together with a unique dataset of undocumented immigrants collected by an Italian NGO - to identify the causal effect of amnesty eligibility on employment probability (unfortunately, wages are not observed in the dataset they use). They find that the prospect of legal status significantly increases the employment probability of those immigrants who are potentially eligible for the amnesty relative to other undocumented immigrants. The size of the effect is equivalent to about twothirds of the increase in employment that undocumented immigrants in their sample normally experience in their first year since arrival in Italy. 


\subsection{Legal Status and Crime}

Although comparatively small with respect to the large body of evidence on the labour market impact of immigration, a growing stream of literature has focused on the effects of immigration on crime, both in the US (Butcher \& Piehl (1998a), Butcher \& Piehl (1998b), Borjas et al. (2010), Spenkuch (2014)) and in Europe (Bianchi et al. (2012); Bell et al. (2013)). If immigrants - and undocumented immigrants in particular - are disadvantaged in the labour market, a standard economic model of criminal activity decision (Becker (1968)) would suggest that they should be more likely to engage in crime. As a matter of fact, legal status may profoundly affect criminal behaviour by altering the relative payoffs of legitimate and illegitimate activities (Fasani et al. (2013)). Nevertheless, theoretical predictions on the effect of legal status on the propensity to engage in crime are ambiguous. By improving labour market prospects, legalisation should reduce the incentives to commit crime. On the other hand, legalised immigrants no longer face the risk of deportation as an additional penalty if caught committing crime, potentially increasing their incentives to engage in illicit behaviour. Some very recent papers have empirically addressed this issue.

In the US context, Baker (2013) and Freedman et al. (2014) study the effect of IRCA legalisation and reform on immigrants' criminal behaviour. Baker (2013) analyses how county crime rates (from Uniform Crime Reports) responded to the number of immigrants legalised in the area (measured with Legalisation Summary Tapes data). Exploiting the quasi-random timing of legalisations as well as the cross-county variation in the intensity of the "legalisation treatment", he tries to isolate the causal effects of legalising immigrants on crime. He finds that legalising one per cent of the population reduces crime by approximately $2 \%-6 \%$, with the effect being primarily concentrated on property crime. Freedman et al. (2014) use individual records from criminal justice in one county in Texas and compare the involvement in crime of Hispanic and non-Hispanic individuals before and after the 1986 IRCA reform in a differencein-differences setting. Given that they do not observe residence status in the data, they use 
Hispanic ethnicity to proxy for undocumented immigrants. Rather than finding a reduction in crime as a consequence of legalisation, they observe that the crime rates of the two groups diverge once the legalisation is concluded, with Hispanic citizens engaging in significantly higher levels of criminal activity. They justify their findings with the notion of the IRCA reform making it harder for undocumented immigrants to find jobs in the US. ${ }^{6}$

Empirical work on legal status and immigrant crime in Europe has exclusively focused on Italy, exploiting a variety of policies that induced exogenous changes in legal status. All these studies show that obtaining legal status significantly reduces immigrants' propensity to commit crime.

The European Enlargement of January 2007 is used by Mastrobuoni \& Pinotti (forthcoming) to compare the criminal behaviour of immigrants from new EU member countries (Romania and Bulgaria) and from candidate member countries (Albania, Bosnia and Herzegovina, Croatia, Kosovo, Macedonia, Montenegro, Serbia, and Turkey). On the 1st of January 2007, the former group switched from being (mostly) undocumented to having European citizen status, while the latter group was not affected. The Enlargement occurred a few months after a mass clemency bill released thousand of detainees from Italian prisons, allowing the authors to set up a difference-in-differences approach and study the recidivism rate of released inmates belonging to the two groups of nationalities. They find a substantial effect of legal status - a $50 \%$ reduction in re-offending rate - that explains up to two-thirds of the observed differences in crime rates between legal and illegal immigrants.

Some peculiar features of the Italian migration policy, instead, provide Pinotti (2014) with a quasi-experimental setting in which to analyse the role of legal status in determining the probability of receiving a criminal charge. The Italian quota system is vastly used to legalise the residence status of undocumented immigrants who are already working in the country rather

\footnotetext{
${ }^{6}$ Apart from the legalisation programme, the IRCA required employers to check their employees immigration statuses and made it illegal for employers to knowingly hire unauthorised immigrants.
} 
than to allow new entrants legitimate access to the Italian labour market (Fasani (2010)). Candidates must apply for working permits through an online electronic procedure held in a single "click-day" of the year, and applications are processed on a first-come, first-served basis until the regional quotas that have been previously set are filled. After having matched applicants' records with police data on criminal charges, Pinotti (2014) develops a regression discontinuity design that compares the criminal behaviour of individuals that applied just before and just after the exhaustion of the quota. His baseline estimates show that the probability of committing a crime increases by approximately 50 per cent for applicants who were denied legal status for a matter of seconds.

Finally, Fasani (2014) looks for evidence of significant drops in immigrant crime rates in the aftermath of a legalisation process. He exploits both geographical variation in the number of immigrants legalised in different Italian regions and time variation coming from the frequency of general amnesty granted in Italy (in 1990, 1995, 1998 and 2002; see Fasani (2010)) during the period he studies (1990-2005). He addresses the potential endogeneity of the regional intensity of the "legalisation treatment" by instrumenting the actual number of legalised immigrants with predicted measures obtained from applications in a previous amnesty. ${ }^{7}$ His findings show that in the year following an amnesty measure, regions in which a higher share of immigrants obtained legal status experienced a decline in immigrant crime rates relative to other regions. The effect is statistically significant but relatively small in magnitude, and it is not persistent.

\subsection{Further Outcomes}

Having legal status may produce consequences for immigrants' behaviour and outcomes beyond their labour market integration and criminal choices.

The household choices of income allocation to consumption, savings and remittances, for instance, are likely to depend on the legal status of their members. Indeed, Amuedo-Dorantes \&

\footnotetext{
${ }^{7}$ The instrument is conceptually similar to the supply-push component instrument proposed by Altonji \& Card (1991) and, since then, widely used in the migration literature.
} 
Mazzolari (2010) look at the impact of the 1986 Immigration Reform and Control Act (IRCA) on remittances flows and suggest that the effect of legal status on remittance decisions depends on migrants' remitting motives. ${ }^{8}$ Using LPS data, they compare remitting behaviour in 1987 (before legalisation) and in 1991 (after legalisation) of LPS respondents. In the absence of a suitable control group, they use a before-after estimation and try to control for any other time-varying factor contemporaneous with IRCA that might have affected migrants' remittance behaviour. Conditional on time-varying economic indicators (the unemployment rate and GDP growth) for migrants' US state of residence and country of origin, they estimate a post-legalisation drop of 8 percentage points in the likelihood of sending remittances and a $29 \%$ drop in the amount remitted. Remarkably, they find no statistically significant post-legalisation changes in the remitting patterns of other Latin American immigrants (that represent about one quarter of their sample). Dustmann et al. (2014) suggest instead that the exposure to higher uncertainty implied by the lack of legal status may lead to different consumption behaviours in documented versus undocumented immigrants. Members of the latter group should engage more in precautionary saving and therefore contract their consumption with respect to comparable immigrants taken from the former group. They analyse the Italian context using survey data that allow the authors to distinguish immigrants by residence status and to measure their income, consumption, savings and remittances decisions. ${ }^{9}$ They address the endogenous selection into legal status, proposing an identification strategy that exploits temporary rainfall shocks in the source country at the time of emigration as an exogenous determinant of initial legal status in the host country. The persistence in legal status links those pre-migration shocks to current legal status. Their IV estimates show that undocumented immigrants consume approximately 41 per cent less than documented immigrants, conditional

\footnotetext{
${ }^{8}$ They argue that if migrants remit mainly for altruistic or savings/investment purposes, legalisation may lead to larger remittance flows as a consequence of improved labour market outcomes and higher income. On the contrary, the acquisition of legal status facilitates family reunification, possibly inducing immigrants to move their close relatives to the host country and thus to reduce their incentives to remit. If remittances are instead motivated by insurance purposes, the reduction in uncertainty experienced by legalised immigrants may reduce their propensity to remit.

${ }^{9}$ We use this dataset in the empirical analysis we present in section 4.2.
} 
on background characteristics: roughly 40 per cent of this decrease is explained by the notion that undocumented immigrants have lower incomes than documented immigrants. In a further empirical exercise, they use variations in deportation risk in different areas of residence to show how undocumented immigrants' consumption reacts to variation in the uncertainty they are exposed to.

If obtaining legal residence status gives immigrants access to the welfare state, immigrants may experience important after-legalisation improvements in different dimensions of their lives. Baker (2010), for instance, focuses on health status (measured with mortality rates) and analyses a vast extension of the coverage of Medicaid and MediCal that took place in the state of California concurrently with the passage of the 1986 IRCA. Immigrants who became legal residents in California also became eligible for public healthcare from which they were previously excluded. Similarly to Baker (2013) (see section 3.2), the identification strategy in Baker (2010) relies on cross-county variation in the number of immigrants legalised. His estimates point to a substantial reduction in mortality rates in counties in which a larger share of the population obtained legal status.

Furthermore, immigrants' educational levels may be influenced by residence status. As a matter of fact, legalisation should reinforce immigrants' incentives to invest in human capital by increasing their returns to education. As far as we know, the only article that investigates this channel is Pan (2012). Besides analysing the impact of the IRCA amnesty on labour market outcomes (see section 3.1), she examines the English-speaking ability of immigrants, finding that male immigrants who could have benefited from the 1986 legalisation were more proficient than those who were (probably) excluded from the amnesty. Bean et al. (2011) suggest that the legal status of parents may produce important effects on the educational attainment of second-generation immigrants. Using data from a survey carried out in Los Angeles in 2004, they show that immigrants whose mothers remained unauthorised have significantly fewer years 
of schooling than comparable immigrants whose mothers managed to obtain legal status (or naturalise).

\section{Labour Market Outcomes and Immigrants' Residence Status: New Evidence from Italy}

We now provide novel evidence of the role played by migrants' residence status in shaping their labour market performance. We use unique survey data from Italy that provide us with repeated cross-sections of a large sample of immigrants and allow us to distinguish between permanent residents, temporary residents and undocumented immigrants. We provide descriptive evidence on differentials in average labour market outcomes across different groups of immigrants. Furthermore, we exploit a general amnesty programme to address concerns of selection into legal status.

\subsection{Undocumented Immigrants in Italy and the 2002 Amnesty}

A substantial presence of undocumented immigrants has been a persistent feature of the Italian migration experience. Italy's large shadow economy, an inconsistent migration policy and its geographical shape and position are all factors that have likely contributed to generate and sustain this pattern (Fasani (2010)). In the attempt to reduce its unauthorised resident population, Italy has often resorted to amnesties, offering seven legalisation programs in the last three decades (in 1986, 1990, 1995, 1998, 2002, 2009 and 2012). Overall, approximately 1.7 million immigrants have received legal status through one of these amnesties, a very large number for a country that currently has a population of approximately 4.3 million immigrants (approximately 7 per cent of the total resident population, up from 2.4 per cent in year 2000). The frequency and size of these general amnesties make Italy an ideal candidate for analysing the consequences of similar policies. 
Legal foreign residents in Italy must hold a residence permit that is issued by the Italian police authorities. This is a renewable document whose duration depends on the reason for entry into Italy (work, family reunification, study, etc.) but does not generally exceed two years. The reason for entry also determines whether the immigrant is allowed to work in Italy. After having been legal residents in Italy for at least five years, immigrants with an income above a certain threshold can apply for permanent resident status (in Italian: "Carta di soggiorno"). Citizens of EU member states do not need any residence permit to live in Italy, although when the transitional periods after the Enlargements of 2004 and 2007 were still in place, citizens from new EU member states were not allowed to work in Italy without a valid working permit. Immigrants can apply for naturalisation only after ten years of continuous and legal residence in Italy (four years for EU citizens) or two years after marrying an Italian citizen. In 2012, approximately half of the documented immigrant population from non-EU countries held a permanent residence permit, while this share was approximately 20 per cent in the early 2000s. Naturalisation rates in Italy are rather low with respect to other European countries: in the 2000-2010 period, there were 4.6 acquisitions of citizenship per thousand people in Italy, whereas the EU average was 17.6 (see OECD (2012)).

As discussed in more detail in section 4.3, our empirical strategy partially relies on the 2002 Italian amnesty. ${ }^{10}$ The amnesty was approved in September 2012 after an intense debate within the government coalition, and applications could be submitted for two months after the law enactment date. Unlike the US amnesties we have discussed above (section 3), the 2002 amnesty was reserved for undocumented immigrants who satisfied a minimum residence requirement (three months) and who were employed at the time of application. As a matter of fact, employers were asked to apply on behalf of their undocumented employees, and the amnesty aimed to simultaneously legalise both the residence status of the migrants and the employment relationship. Employers could be firms, Italian citizens or immigrants with permanent residence

\footnotetext{
${ }^{10}$ See Devillanova et al. (2014) for a detailed description of this legalisation programme .
} 
status in Italy: when submitting the application, they would pay a fine (roughly equivalent to three months of social contributions) and could not then be prosecuted for having unlawfully employed migrants in the past. On the other hand, the submission of false statements or documents to the Italian authorities was considered a criminal offence punishable by fines and detention. Successful applicants would receive a renewable two-year work and residence permit linked to the initial employer. In spite of the hurdle created by the direct involvement of employers in the application process, the 2002 amnesty was the largest legalisation process ever held in Italy, receiving more than 700 thousand applications and legalising approximately 640 thousand immigrants. This is a huge number for a country that hosted fewer than 1.5 million documented immigrants in 2002, suggesting a very high take-up rate among undocumented immigrants (although precise estimates are not available). Given the large number of applications received, it took about approximately two years to process all of them, and some applicants had to wait until 2004 before receiving an answer from the Italian authorities (and, eventually, a working permit).

\subsection{Data and Descriptive Statistics}

We use data from an annual survey run by an Italian research foundation called ISMU. ${ }^{11}$ The survey began in 2001 and was administered to around 8,000 immigrants in each wave. The ISMU survey uses an intercept point survey methodology based on the tendency of immigrants to cluster in certain locations (Blangiardo (2008), McKenzie \& Mistiaen (2009)). ${ }^{12}$ It interviews a representative sample of both legal and illegal migrants residing in the Italian region of Lombardy, one of the wealthiest and most populated Italian regions that hosts a substantial

\footnotetext{
${ }^{11}$ The ISMU (Initiatives and Studies on Multiethnicity) Foundation is an autonomous and independent organisation promoting studies, research and projects on multi-ethnic and multi-cultural society, and focussing in particular on the phenomenon of international migrations (www.ismu.org).

${ }^{12}$ The first step of this methodology is to create a list of popular intercept points (e.g., ethnic shops and gatherings, churches, healthcare facilities) and then randomly select the meeting points and the migrants who visit them for interviews. At each location, interviewees are asked how often they visit any of the other meeting points, which allows ex-post selection probabilities to be computed into the sample. See Accetturo \& Infante (2010) and Dustmann et al. (2014) for a description of these data.
} 
share of the immigrant population residing in Italy. ${ }^{13}$ The survey questionnaire contains a variety of questions on individual characteristics (e.g., demographics, labour market outcomes, residence status) and household characteristics (e.g., number of household members in Italy, family members abroad, housing). The ISMU survey is specifically designed to elicit the truthful reporting of residence status, and it allows interviewees to be distinguished into three groups: undocumented immigrants, temporary residents and permanent residents. ${ }^{14}$ Moreover, the waves conducted in 2003 and 2004 collected information regarding participation in the 2002 amnesty, and we can identify both the undocumented immigrants who applied for amnesty (but were still waiting for their application to be processed) and those who were granted legal status through the amnesty. In our empirical analysis, we compare the labour market outcomes of these different groups of immigrants.

We construct four measures of labour market performance: (i) the probability of being employed, (ii) log monthly earnings, (iii) the probability of having a job with a formal employment contract and (iv) the probability of having a low-quality occupation. ${ }^{15}$ The probability of being employed is computed only for immigrants who report to be actively part of the labour force, while the other three outcomes are analysed only for the subpopulation of employed immigrants. ${ }^{16}$ We measure occupation quality with two commonly used socioeconomic indexes of occupational status: the International Socio-Economic Index of Occupational Status (ISEI) and the Standard International Occupational Prestige Scale (SIOPS) (Ganzeboom \& Treiman (1996)). ${ }^{17}$ After matching the occupations in the ISMU survey with the corresponding values

\footnotetext{
${ }^{13}$ In the period we study in this paper (early 2000s), Lombardy accounted for approximately $20 \%$ of the national GDP and for approximately $16 \%$ of the Italian population, it hosted about one-fourth of the documented immigrants residing in Italy and received about 22 per cent of the applications submitted for the 2002 amnesty.

${ }^{14}$ Permanent residents include a minority of individuals that have acquired Italian citizenship.

${ }^{15}$ Unfortunately, the ISMU surveys do not collect information on hourly wages and hours worked.

${ }^{16}$ Students, housewives and elderly people (over 65) are disproportionately present among the population of permanent residents - relative to temporary and undocumented immigrants - and, if kept in the sample, they would complicate the interpretation of any comparison across groups.

${ }^{17}$ The former index captures the attributes of occupations that convert education into income, while the latter measures the level of prestige associated with occupations. Both indexes assign a numerical value to each occupation in the International Standard Classification of Occupations (ISCO88), with higher values corresponding to occupations that reward education more or are more prestigious.
} 
of ISEI and SIOPS taken from Ganzeboom \& Treiman (1996) (see Appendix table A 1), we consider workers to have a low-quality occupation if the associated SIOPS/ISEI index is below 30.

In our empirical analysis, we use the ISMU survey for the years 2001-2007. The full sample contains 49,922 observations that become 38,594 when we restrict the analysis to immigrants with at most ten years of residence in Italy. When we focus on the two years after the amnesty (2003 and 2004), the sample includes 10,164 observations. Table 1 reports descriptive statistics for our estimating sample, distinguishing immigrants by their residence status (permanent residents, temporary residents and undocumented immigrants). The three groups account for 21, 61 and 18 per cent of the sample, respectively. The upper panel of table 1 reports demographic characteristics. The share of women is around one-third in all groups. Both age and the duration of residence in Italy increase with the "stability" of residence status. The average age for permanent, temporary and undocumented residents is $38.1,33.6$ and 30.7 , respectively, while the average number of years in Italy is $12,6.6$ and 2.3, respectively. Immigrants with permanent residence status are more educated than those in the other two groups (approximately 40 per cent with primary or no formal education, 40 per cent with secondary education and the remaining 20 per cent with tertiary education), whereas the distribution of education is very similar for temporary and undocumented immigrants (in both groups, approximately 50 per cent of the sample has primary or no formal education, 40 per cent has secondary education and 10 per cent has tertiary education). The distribution by area of origin is fairly homogenous across different groups.

A substantial degree of heterogeneity by residence status is evident when we look at labour market outcomes (bottom panel of table 1). As expected, having temporary residence status and, even more dramatically, lacking legal status are associated with worse performance in the labour market. The share of employed active workers is 96 per cent for permanent residents, 92 per cent for temporary residents and 79 per cent for unauthorised immigrants, while the average 
monthly earnings for employed immigrants are approximately 1,230 euro, 1,010 euro and 820 euro for the three groups, respectively. The vast majority of immigrants with legal status work with a formal employment contract (94 and 90 per cent for permanent and temporary residents, respectively), while this share drops to 15 per cent for undocumented immigrants. ${ }^{18}$ Finally, the share of workers having a low-quality occupation (ISEI index below 30) increases from 52 per cent for permanent residents, to 64 per cent for temporary residents and 72 per cent for undocumented immigrants. The pattern is similar when the SIOPS index is used. Appendix table A 1 allows us to analyse in more detail the distribution of immigrants across different occupations.

\subsection{Empirical Strategy}

Our empirical analysis is developed in three steps. In the first two, we provide descriptive evidence on differentials in average labour market outcomes across different groups of immigrants, while in the last one, we exploit the 2002 Italian amnesty in order to identify the causal effect of legal status.

Undocumented, temporary and permanent residents. We first compare labour market outcomes of the three groups of immigrants discussed in the previous section. Holding permanent residents as benchmark, we estimate the following equation:

$$
y_{i t p}=\alpha_{0}+\alpha_{1} t_{e m p} p_{i t p}+\alpha_{2} u n d o c_{i t p}+\boldsymbol{X}_{i t p} \boldsymbol{\alpha}+\delta_{t}+\eta_{p}+u_{i t p}
$$

where: $y_{i t p}$ is a labour market outcome of immigrant $i$ interviewed in year $t$ and residing in the Italian province $p ; \alpha_{0}$ is a constant; temp $p_{i t p}$ and $u n d o c_{i t p}$ are dummies identifying immi-

\footnotetext{
${ }^{18} \mathrm{As}$ a matter of fact, the Italian legislation prevents immigrants that lack legal residence status from having a valid contract of employment, implying that the share of undeclared workers should be at 100 per cent among this latter group of immigrants. Immigrants' responses to this question should therefore be interpreted by taking into account that some of the interviewees may confound stable and continuative employment relationships with having a valid employment contract.
} 
grants who have temporary residence status and illegal status, respectively; $\boldsymbol{X}_{i t p}$ is a matrix of individual controls; $\delta_{t}$ are year dummies; $\eta_{p}$ are Italian province of residence dummies; $u_{i t p}$ is an idiosyncratic shock. The coefficients of interest in this equation are $\alpha_{1}$ and $\alpha_{2}$ : they identify how labour market outcomes of immigrants with temporary residence status and undocumented immigrants, respectively, differ on average from those of comparable immigrants with permanent residence status. This part of the analysis is purely descriptive: we do not have an identification strategy to address the selection into residence status and the coefficients we estimate are not necessarily pinning down the causal impact of migrants' residence status on their labour market performance.

2002 amnesty: applicants, non-applicants and temporary residents. The second part of the analysis exploits the 2002 amnesty in order to gain further insight on the role of legal status in determining the labour market outcomes of immigrants. We now exclude from the analysis immigrants with permanent status. We use data from year 2003 and 2004, where we can distinguish unauthorised immigrants who applied for the 2002 amnesty (and are still waiting for their application to be processed) and those who did not. We restrict the sample to those that arrived in 2002 or before in order to include everyone who was potentially entitled to apply for the amnesty. ${ }^{19}$ We now hold immigrants with temporary residence status as the benchmark group, and we estimate the following equation:

$$
y_{i t p}=\beta_{0}+\beta_{1} u n d o c_{-} N O a p p l_{i t p}+\beta_{2} u n d o c_{\_} a p p l_{i t p}+\boldsymbol{X}_{i t p} \boldsymbol{\beta}+\delta_{t}+\eta_{p}+\nu_{i t p}
$$

Similarly to equation (1), $y_{i t p}$ is a labour market outcome of immigrant $i$ interviewed in year $t$ and residing in the Italian province $p ; \beta_{0}$ is a constant; undoc_NOappl $l_{i t p}$ and undoc_appl $l_{i t p}$

\footnotetext{
${ }^{19}$ As a matter of fact, undocumented immigrants that arrived after the 11th of June 2002 were theoretically ineligible for amnesty (see Devillanova et al. (2014)). Nevertheless, at least some of them may have been able to find an employer willing to support their application before the deadline for submissions expired (i.e., the 13th of November 2002). Our findings are basically identical if we use only immigrants that arrived in Italy in 2001 or earlier.
} 
are dummies that identify undocumented immigrants who did not apply and applied for the 2002 amnesty, respectively; $\boldsymbol{X}_{i t p}$ is a matrix of individual controls; $\delta_{t}$ are year dummies; $\eta_{p}$ are Italian province of residence dummies; $\nu_{i t p}$ is an idiosyncratic shock. We are now interested in coefficients $\beta_{1}$ and $\beta_{2}$, identifying differences in average labour markets between immigrants with temporary residence status and undocumented immigrants who did not apply for the 2002 amnesty and those who did apply, respectively. As before, the endogenous selection into status prevents us from providing a causal interpretation of our estimated coefficients.

2002 amnesty: only applicants. In our third empirical exercise, we directly address the selection into migration status and identify arguably causal parameters. As discussed in section 4.2, the ISMU surveys conducted in the years 2003 and 2004 not only allow us to split undocumented immigrants into applicants and non-applicants for the 2002 amnesty but also identify immigrants with temporary residence status that were legalised through the 2002 amnesty. We can now exclusively concentrate on 2002 amnesty applicants and compare the outcomes of those who were legalised and those who were still waiting for legalisation in 2003-2004. We estimate the following equation:

$$
y_{i t p}=\gamma_{0}+\gamma_{1} \text { legalised }_{i t p}+\boldsymbol{X}_{i t p} \boldsymbol{\gamma}+\delta_{t}+\eta_{p}+\epsilon_{i t p}
$$

where $y_{i t p}$ is a labour market outcome of immigrant $i$ interviewed in year $t$ and residing in the Italian province $p$, while legalised ${ }_{i t p}$ is a dummy equal to one if the applicant has been granted legal status and zero if she is still waiting for an answer regarding her application. As for the previously estimated equations: $\gamma_{0}$ is a constant term; $\boldsymbol{X}_{i t p}$ is a matrix of individual controls; $\delta_{t}$ are year dummies; $\eta_{p}$ are Italian province of residence dummies; $\epsilon_{i t p}$ is an idiosyncratic shock.

By only considering the population of applicants, we do not need to worry about differences in unobservable characteristics that potentially drove the process of selection-into-amnesty and could instead make applicants and non-applicants hardly comparable. Our strategy is analogous 
to the approach used by Angrist (1998) to estimate the labour market impact of voluntary military service by matching accepted and rejected applicants on a large set of observable characteristics. Although legal status was not randomly assigned to amnesty applicants, the institutional setting of the 2002 amnesty arguably created quasi-randomness in the timing of legalisations that we exploit to achieve identification. As discussed in section 4.1, the 2002 amnesty received an unforeseen large number of applications that required up to two years to be screened and resolved. Insofar as immigrants could not influence the time taken by the Italian authorities to process their applications, we should not have any systematic difference in unobservable characteristics between legalised and "waiting-for-legalisation" applicants. More specifically, our identifying assumption implies that the only difference between these two groups of applicants is the extent to which the concession of legal status was delayed by idiosyncratic factors of the screening process: the individuals who have legal status in our sample are those who were "lucky" enough to have their applications evaluated and approved before the ISMU surveys were run in spring 2003 and spring $2004 .{ }^{20}$

Although immigrants could not determine the speed of processing their applications, they could endogenously choose the date of submission of the application during the two-month window of the application period (11 September 2002 - 13 November 2002). Applications were (at least in theory) processed following the order of submission: some selection bias may still be present if immigrants that were more motivated and those with a better performance in the labour market were faster in persuading their employers to submit their applications. When assessing this concern, one should first note that the relative position of the applicant among the pool of all applicants in her province - and not the date of submission per se - is what determined the waiting time for having the application evaluated. This clearly introduces an element of randomness, given that the timing of the submission of all the other immigrants

\footnotetext{
${ }^{20}$ In our empirical analysis, we address the concern that individuals that are still waiting for legalisation in 2004 may be different in unobservables with respect to those who obtained legal status by running separate regressions in which we first use only data from the 2003 survey and then data from both the 2003 and 2004 waves.
} 
residing in the area falls beyond the control of each single immigrant. However, an individual filing her application in the first days of the submission window will substantially increase the probability of her application being processed earlier with respect to someone submitting the application in the last days. We can expect these two individuals to differ along many unobservable dimensions. Still, if applicants legalised earlier have "better" unobservables than those who are still waiting for a resolution on their application - as it is reasonable to expect we would overestimate the causal effect of legal status. ${ }^{21}$

We estimate the three models above with OLS regressions (for log earnings) and Linear Probability Model regressions (for the binary outcomes), and we always use heteroscedasticityrobust standard errors. In all regressions, we control for "Baseline controls" that include year dummies and province of residence dummies (there are 11 provinces in the Lombardy region). Furthermore, we gradually add individual controls (gender, age, age squared, education dummies, years since arrival in Italy) and a full set of country of origin dummies (151 in our sample).

\subsection{Results}

Undocumented, temporary and permanent residents. We first report our empirical findings from estimating equation (1). Table 2 reports estimates for the probability of being employed (columns 1-4) and log monthly earnings (columns 5-8). In order to make these three groups of immigrants more comparable and ensure common support, in columns 1-3 and 5-7, we

\footnotetext{
${ }^{21}$ In our view, any reasonable hypothesis on the functioning of the applications' evaluation would lead to expect, if anything, an overestimation of the effect of becoming a legal resident. Suppose, for instance, that the Italian authorities adopted different routines in the process of reviewing applications. If they started assessing the applications that looked more founded (e.g., higher wages, better occupations, larger firms, etc.), we would have that those legalised earlier have a stronger labour market performance than those still waiting for a response. If, on the contrary, they first eliminated applications patently unfounded (e.g., those with fake employers), they would just make legalised applicants and "waiting-for-legalisation" applicants more similar to each other, as both groups would be left only with individuals that are truly eligible for legalisation. In addition, one may worry about how rejections may possibly affect estimation results. This seems to be a minor issue given that the acceptance rate for the 2002 amnesty was extremely high at approximately 95 per cent. Nevertheless, rejections would again bias our results in the direction of finding better labour market outcomes for the applicants who were granted legal status: among the immigrants who are still waiting for an answer, we have both future successful and future unsuccessful applicants, while among the legalised, we only have the former, who are likely to have a better labour market performance than the latter.
} 
restrict the sample to immigrants with at most ten years of residence in Italy. Results from our preferred specification are reported in columns 3 and 7, where we condition year dummies, province dummies, individual controls and country of origin dummies. In columns 4 and 8 , we remove the restriction on the maximum duration of permanence in Italy.

According to unconditional estimates (column 1), temporary immigrants have a significantly lower probability of being employed than permanent immigrants. Nevertheless, the coefficient becomes positive and remains highly significant when individual controls are included in the specification, suggesting that temporary immigrants have individual characteristics (such as shorter permanence in Italy) that make them less likely to be employed. According to the estimates in column 3, temporary immigrants are about two percentage points more likely to have a job than comparable permanent residents, although the difference becomes insignificant when we use the full sample (column 4). Monthly earnings for temporary residents are significantly lower than they are for permanent residents: 3 per cent lower in our preferred specification (column 7) and almost 6 per cent when we use the full sample. As expected, immigrants without legal status are significantly less likely to be employed and, conditional on having a job, they have significantly lower earnings than permanent residents. In our preferred specifications (columns 3 and 7), we find that undocumented immigrants are 4 percentage points less likely to be employed and, when employed, they earn approximately 16 per cent (18 log points) less than comparable immigrants with permanent legal status. Excluding individual controls (columns 1 and 5) substantially increases these estimated gaps, implying that the personal characteristics of undocumented immigrants negatively affect their labour market performance in Italy. In the last two rows of table 2 , we test for the equality of the coefficients on the temporary resident and undocumented status dummies. In all cases, we conclude that undocumented immigrants have significantly lower employment probability and lower earnings than immigrants with temporary residence status.

In table 3, we analyse the differences in the quality of employment. As explained above, we use three indicators: (i) being in regular employment (columns 1-4), (ii) having an occupation 
with an ISEI index below 30 (columns 5-8) and (iii) having an occupation with a SIOPS index below 30 (columns 9-12). The structure of the table is analogous to that of the previous one. In our preferred specification, we find no significant difference in the probability of working in the underground sector between temporary and permanent residents (column 3). Nevertheless, the former are about 8 percentage points more likely to have a low-quality occupation (columns 7 and 11). As it is obvious to expect from the fact that undocumented immigrants cannot have a recorded job in Italy, column 3 shows that they are about 70 percentage points less likely to be working with a formal contract of employment than comparable permanent residents. The quality of their occupations is also significantly lower: the probability of having a job associated to an ISEI (SIOPS) index below thirty is about 14 (10) percentage points higher than for permanent residents (columns 7 and 11). In the last two rows of Table 3, we test for the equality of coefficients on the temporary resident and undocumented status dummies: immigrants lacking legal status have a significantly higher probability of being employed without a formal contract than temporary residents, while the difference in the quality of the occupation held is significant with the ISEI index (column 8) but not with the SIOPS index (column 12).

2002 amnesty: applicants, non-applicants and temporary residents. We now present the results from estimating equation (2), where we compare undocumented immigrants who applied for the 2002 amnesty, undocumented immigrants who did not apply, and immigrants that had temporary residence status. We now restrict the analysis to years 2003 and 2004, and we include only immigrants who arrived in Italy at the latest in year 2002. The structure of the tables is analogous to our previous empirical exercise. Table 4 shows that undocumented immigrants who did not apply for the amnesty have a significantly lower probability of being employed (-0.15 p.p.) and lower earnings (-0.26 log points) than comparable temporary residents. We find no significant difference in employment probability, instead, between undocumented immigrants who applied for the 2002 amnesty and temporary immigrants (column 3), although the former earn about 4 per cent less than the latter (column 7). When we consider the quality of 
employment in table 5, we find that non-applicant undocumented immigrants have a dramatically higher probability of working in the shadow economy (77 percentage points higher, column 3), although they do not have occupations of significantly lower quality (columns 7 and 11). Amnesty applicants also have a significantly higher probability of working in an unrecorded job position than temporary residents. ${ }^{22}$ Remarkably, undocumented applicants have occupations of significantly lower quality than temporary residents, being 7 (5) per cent more likely to have an occupation with ISEI (SIOPS) below thirty.

2002 amnesty: only applicants. Finally, we discuss our estimates from equation (3), where we only consider applicants for the 2002 amnesty and we compare labour market outcomes for those legalised and those not yet legalised. in order to address the reasonable concern that individuals who are still waiting for legalisation in 2004 may be different in unobservables with respect to those who have already obtained legal status, we run separate regressions in which we first use only data from the 2003 survey and then data from both the 2003 and 2004 waves. In appendix table A 2, we test for the randomness of legalised status by comparing the average observable characteristics of legalised immigrants and those "waiting for legalisation". The two groups of immigrants look very similar, although we find some mean values that are statistically different from each other. In particular, there is a substantially larger share of women among the legalised applicants than among those not legalised yet (40 per cent versus 34, when we consider only the 2003 wave; but the gap halves when we use both 2003 and 2004 data), and the former group is about one year older than the latter. In order to take into account these differences, in our regression analysis, we will always condition on individual characteristics. Remarkably, table 6 suggests that there is little difference in employment and earnings between the two groups: legalised immigrants have slightly better labour market

\footnotetext{
${ }^{22}$ The estimated coefficient is smaller in absolute value than the coefficient for non-applicants and significantly different from it (minus 0.28 versus minus 0.77 ; column 3). Given that undocumented immigrants cannot technically have a formal employment contract in Italy, this difference between applicants and non-applicants suggests that the former anticipate that their positions will (possibly) be legalised in the near future.
} 
outcomes than applicants who are still waiting for their applications to be processed, but the differences are tiny (two percentage points more in employment and three log points more in earnings) and only marginally significant. Table 7 instead shows a clear - although fairly mechanical - effect of the legalisation: immigrants who were granted legal status are 25-30 percentage points more likely to have a regular contract with their employers (columns 1-4). ${ }^{23}$ No strong evidence of upgrading in the quality of occupations is instead found in the remaining columns of 7: all coefficients are negative, but they are small and marginally significant or insignificant. Taken together, the estimates reported in table 6 and in table 7 suggest that being granted legal status seems to make little difference for the immigrants. As discussed in section 4.3, any reasonable concern about endogenous selection into legal status would lead to an exaggeration of its true effect: if anything, our tiny and marginally significant estimates on employment probability and earnings are an upper bound of the actual causal effect. In both table 6 and table 7, restricting the sample to only the 2003 wave or using both 2003 and 2004 waves does not substantially change the estimated coefficients.

\subsection{Interpreting the Results: is Legal Status Irrelevant?}

The descriptive part of our analysis (i.e., the estimation of equations (1) and (2)) confirms that immigrants with a more stable residence status in the host country have better outcomes in the labour market. These findings are consistent with the literature on naturalisations (Bratsberg et al. (2002); Mazzolari (2009)) and transitions from temporary to permanent residence status (Mukhopadhyay \& Oxborrow (2012)).

On the contrary, when we (arguably) identify the causal impact of legal status on amnesty applicants' outcomes, we fail to find a sizeable and significant effect on employment, earnings and occupational quality, while observing a fairly mechanical negative effect on being in undeclared employment. In order to interpret these latter results, we need to consider the specific

\footnotetext{
${ }^{23}$ This is an obvious outcome of a legalisation process that jointly legalised both immigrants' residence status and their employment relationships (see section 4.1).
} 
design of the amnesty we are studying and the fact that we are are looking at very short-term effects of legalisation.

As discussed in section 4.1, the 2002 amnesty required the immigrants to satisfy a minimum residence requirement and to be in employment at the moment of applying for legal status. The presence of an employment requirement is expected to generate a shift in the labour supply of undocumented immigrants and makes this amnesty different from the legalisation programs we have discussed in the US context. ${ }^{24}$ Indeed, when the amnesty is announced, undocumented immigrants who satisfy the residence requirement will suddenly attribute substantially more value to being employed than before, given that having a job now also implies the possibility of becoming legal (in addition to the salary one earns). If potential applicants attach a positive value to becoming a legal resident, they will try their best to maintain their jobs (if employed) or to find a job (if unemployed). In order to do that, they will be probably ready to accept lower wages, longer working hours and less attractive occupations: one may therefore observe a sharp increase in the employment rate of amnesty applicants before legalisation (as in Devillanova et al. (2014)) and possibly a reduction in their wages and in the quality of their occupations and working conditions. Once a legal status is obtained, immigrants will reap the benefits of having more occupational mobility, access to welfare, zero risk of deportation, etc., and they will start bargaining for higher salaries, looking for better job matches, moving into better occupations, etc. After legalisation, therefore, there should be a progressive adjustment towards better occupations and higher wages and possibly a reduction in the employment rate. This latter process is gradual because it takes time to renegotiate working conditions with existing employers or to find an alternative employer.

Our empirical findings are fully consistent with these theoretical predictions. Indeed, tables 4 and 5 show that amnesty applicants experience a sizeable increase in their probability of being employed: they have an employment rate that is substantially higher than non-applicants and

\footnotetext{
${ }^{24}$ Devillanova et al. (2014) provide a theoretical framework and a detailed discussion of the effects that such an amnesty - relative to amnesties that exclusively conditioned eligibility on some minimum residence requirement (e.g., IRCA) - would produce on the labour demand and supply of undocumented immigrants.
} 
not significantly different from that of temporary residents. Their earnings are also higher than those of non-applicants (but still significantly lower than those of temporary residents), but they seem to have accepted a downgrade in the quality of their occupations, which is significantly lower than that of both non-applicants and temporary residents. When applicants become legal - see results in tables 6 and 7 - the only immediate effect is moving out from the shadow economy, while the other outcomes (employment, earnings and occupational quality) experience only marginal (and hardly significant) improvements. Indeed, employment can hardly increase more (given that it has already reached the level of temporary residents), while the positive effect on earnings and occupation will probably become visible only in the medium-long run (we only use data for years 2003 and 2004). In particular, in the context of the 2002 Italian amnesty, the immigrant received a two-year working and residence permit that was initially tied to the employer who had supported the application. Therefore, the earnings and occupational status that we observe in our data had been probably determined by the bargaining process that took place before the legalisation and do not yet reflect the improved residence status of the immigrants.

Overall, our results suggest that obtaining legal status matter for the labour market outcomes of immigrants. However, the specific design of the amnesty analysed determines the timing and progression of the effects. An amnesty with an employment requirement creates the incentives for a shift in the labour supply of undocumented immigrants, increases their employment rate even before legalisation and possibly reduces their wages and occupation quality. Once legal status is secured, the immigrant will then gradually move to higher-quality and better-paid occupations. This pre-legalisation effect on immigrants' labour supply does not exist for amnesties that exclusively condition eligibility for legal status on a minimum period of residence (e.g., LAW-IRCA), implying that our empirical results would have been different if the 2002 Italian amnesty had such a design.

Beyond amnesties, it is worth stressing that such a supply-side mechanism is in place for 33 
any of the widespread temporary workers programs or other migration schemes that condition the issuance and/or renewal of a visa on having an employer that is willing to support the application. Our empirical analysis is therefore also informative about the effect of those policies.

\section{Conclusions}

The debate on the future of the 11.5 undocumented immigrants estimated to be currently residing in the US unequivocally demonstrates the need for a better understanding of the role of legal status in determining immigrants' outcomes, choices and behaviour. Not only do we know relatively little about the consequences of lacking legal status but we also know possibly even less about the effects that different policies that affect legal status may produce. Academic research contributes to informing this and similar debates in other receiving countries, but substantial work still needs to be done.

As the literature review proposed in this paper shows, most of the initial articles in this new field of research have focused on one single policy episode - the Legally Authorised Workers (LAW) programme introduced by the 1986 IRCA in the US - and predominately used the same sources of data. Recent years, instead, have witnessed a promising expansion and acceleration of the research conducted in this area: an increasing number of papers has considered new policy experiments, focused on new outcomes, explored novel datasets and proposed innovative and rigorous identification strategies. All of these improvements suggest that many of the policyrelevant questions concerning legal status and amnesties will soon be addressed and possibly answered. 


\section{References}

Accetturo, A. \& Infante, L. (2010), 'Immigrant Earnings in the Italian Labour Market', Giornale degli Economisti, GDE (Giornale degli Economisti e Annali di Economia), Bocconi University 69(1), 1-28.

Altonji, J. J. \& Card, D. (1991), The effects of immigration on the labor market outcomes of less-skilled natives, in J. M. Abowd \& R. B. Freeman, eds, 'Immigration, Trade and Labor', University of Chicago Press.

Amuedo-Dorantes, C., Bansak, C. \& Raphael, S. (2007), 'Gender differences in the labor market: Impact of irca's amnesty provisions', American Economic Review 97(2), 412-416.

Amuedo-Dorantes, C. \& Mazzolari, F. (2010), 'Remittances to latin america from migrants in the united states: Assessing the impact of amnesty programs', Journal of Development Economics 91(2), 323 - 335 .

Angrist, J. D. (1998), 'Estimating the labor market impact of voluntary military service using social security data on military applicants', Econometrica 66(2), 249-288.

Baker, S. (2010), Effects of Legal Status and Health Service Availability on Mortality, Discussion Papers, Stanford Institute for Economic Policy Research 09-018, Stanford Institute for Economic Policy Research.

Baker, S. (2013), Effects of Immigrant Legalization on Crime: The 1986 Immigration Reform and Control Act, Discussion Papers 12-012, Stanford Institute for Economic Policy Research.

Barcellos, S. H. (2010), Legalization and the Economic Status of Immigrants, Working Papers, RAND Corporation Publications Department 754, RAND Corporation Publications Department. 
Bean, F. D., Leach, M. A., Brown, S. K., Bachmeier, J. D. \& Hipp, J. R. (2011), 'The educational legacy of unauthorized migration: Comparisons across u.s.-immigrant groups in how parents status affects their offspring1', International Migration Review 45(2), 348-385.

Becker, G. S. (1968), 'Crime and punishment: An economic approach', The Journal of Political Economy 76(2), 169-217.

Bell, B., Fasani, F. \& Machin, S. (2013), 'Crime and immigration: Evidence from large immigrant waves', The Review of Economics and Statistics 95(4), 1278-1290.

Bianchi, M., Buonanno, P. \& Pinotti, P. (2012), 'Do immigrants cause crime?', Journal of the European Economic Association 10(6), 1318-1347.

Blangiardo, G. C. (2008), The centre sampling technique in surveys on foreign migrants. the balance of a multi-year experience, Working Papers 12, United Nations Statistical Commission and EUROSTAT.

Borjas, G. J., Grogger, J. \& Hanson, G. H. (2010), 'Immigration and the Economic Status of African-American Men', Economica 77(306), 255-282.

Borjas, G. J. \& Tienda, M. (1993), 'The employment and wages of legalized immigrants', International Migration Review 27(4), 712-747.

Bratsberg, B., Ragan, J. F. \& Nasir, Z. M. (2002), 'The Effect of Naturalization on Wage Growth: A Panel Study of Young Male Immigrants', Journal of Labor Economics 20(3), 568597.

Butcher, K. F. \& Piehl, A. M. (1998a), 'Cross-city evidence on the relationship between immigration and crime', Journal of Policy Analysis and Management 17(3), 457-493.

Butcher, K. F. \& Piehl, A. M. (1998b), 'Recent immigrants: Unexpected implications for crime and incarceration', Industrial and Labor Relations Review 51(4), 654-679. 
Casarico, A., Facchini, G. \& Frattini, T. (2012), Spending More is Spending Less: Policy Dilemmas on Irregular Migration, Development Working Papers 330, Centro Studi Luca dÁgliano, University of Milano.

Chiswick, B. (1988), Illegal Aliens: Their Employment and Employers, Upjohn Institute for Employment Research, Kalamazoo, Michigan.

Devillanova, C., Fasani, F. \& Frattini, T. (2014), Employment of Undocumented Immigrants and the Prospect of Legal Status: Evidence from an Amnesty Program, CReAM Discussion Paper Series 1415, Centre for Research and Analysis of Migration (CReAM), Department of Economics, University College London.

Dustmann, C., Fasani, F. \& Speciale, B. (2014), Legal status and consumption behavior of immigrant households. mimeo.

Fasani, F. (2010), The quest for "la dolce vita"? undocumented migration in italy, in A. Triandafyllidou, ed., 'Irregular Migration in Europe: Myths and Realities', Ashgate, chapter 9 , pp. 167-186.

Fasani, F. (2014), Immigrant crime and legal status: Evidence from repeated amnesty programs. mimeo.

Fasani, F., Gazz, L., Pinotti, P. \& Tonello, M. (2013), Immigration policy and crime, Report for the xv european conference, Fondazione Rodolfo Debenedetti.

Freedman, M., Owens, E. \& Bohn, S. (2014), Immigration, employment opportunities, and criminal behavior.

Ganzeboom, H. B. \& Treiman, D. J. (1996), 'Internationally comparable measures of occupational status for the 1988 international standard classification of occupations', Social Science Research 25(3), $201-239$. 
Hoefer, M., Rytina, N. \& Baker, B. (2012), Estimates of the unauthorized immigrant population residing in the united states: January 2011, Population estimates, U.S. Department of Homeland Security -.

Hotchkiss, J. L. \& Quispe-Agnoli, M. (2009), Employer monopsony power in the labor market for undocumented workers, WP 14, Federal Reserve Bank of Atlanta.

Kaushal, N. (2006), 'Amnesty programs and the labor market outcomes of undocumented workers', Journal of Human Resources 41(3), 631-647.

Kossoudji, S. A. \& Cobb-Clark, D. A. (2000), 'Irca's impact on the occupational concentration and mobility of newly-legalized mexican men', Journal of Population Economics 13(1), 8198.

Kossoudji, S. A. \& Cobb-Clark, D. A. (2002), 'Coming out of the shadows: Learning about legal status and wages from the legalized population', Journal of Labor Economics 20(3), 598-628.

Lofstrom, M., Hill, L. \& Hayes, J. (2013), 'Wage and mobility effects of legalization: Evidence from the new immigrant survey*', Journal of Regional Science 53(1), 171-197.

Lozano, F. A. \& Sorensen, T. A. (2011), The Labor Market Value to Legal Status, IZA Discussion Papers 5492, Institute for the Study of Labor (IZA).

Massey, D. (1987), 'Do undocumented immigrants earn lower wages that legal immigrants: New evidence from mexico', International Migration Review 21, 236-274.

Mastrobuoni, G. \& Pinotti, P. (forthcoming), 'Legal status and the criminal activity of immigrants', American Economic Journal: Applied Economics .

Mazzolari, F. (2009), 'Dual citizenship rights: do they make more and richer citizens?', Demography 46(1), 169-191. 
McKenzie, D. J. \& Mistiaen, J. (2009), 'Surveying migrant households: a comparison of censusbased, snowball and intercept point surveys', Journal of the Royal Statistical Society Series A 172(2), 339-360.

Mukhopadhyay, S. \& Oxborrow, D. (2012), 'The Value of an Employment-Based Green Card', Demography 49(1), 219-237.

OECD (2012), International migration outlook 2012, Technical report, OECD Publishing.

Orrenius, P., Zavodny, M. \& Kerr, E. (2012), 'Chinese immigrants in the u.s. labor market: Effects of post-tiananmen immigration policy', International Migration Review 46(2), 456482.

Pan, Y. (2012), 'The impact of legal status on immigrants earnings and human capital: Evidence from the irca 1986', Journal of Labor Research 33(2), 119-142.

Pinotti, P. (2014), Clicking on heaven's door: The effect of immigrant legalization on crime.

Rivera-Batiz, F. L. (1999), 'Undocumented workers in the labor market: An analysis of the earnings of legal and illegal mexican immigrants in the united states', Journal of Population Economics 12(1), 91-116.

Sampaio, B., Sampaio, G. R. \& Sampaio, Y. (2013), 'On estimating the effects of immigrant legalization: Do u.s. agricultural workers really benefit?', American Journal of Agricultural Economics 95(4), 932-948.

Spenkuch, J. L. (2014), 'Understanding the impact of immigration on crime', American Law and Economics Review 16, 177219. 


\section{Tables}

Table 1: Descriptive statistics, by residence status

\begin{tabular}{|c|c|c|c|c|c|c|c|}
\hline & & \multicolumn{6}{|c|}{ Residence Status } \\
\hline & & \multicolumn{2}{|c|}{ Permanent } & \multicolumn{2}{|c|}{ Temporary } & \multicolumn{2}{|c|}{ Undocumented } \\
\hline & & mean & std dev & mean & std dev & mean & std dev \\
\hline & & & Den & graphic & haracteris & ics & \\
\hline \multicolumn{2}{|l|}{ Female } & 0.33 & 0.47 & 0.34 & 0.47 & 0.35 & 0.48 \\
\hline \multicolumn{2}{|l|}{ Age } & 38.09 & 7.81 & 33.59 & 7.93 & 30.73 & 8.09 \\
\hline \multirow[t]{4}{*}{ Education: } & No & 0.09 & 0.29 & 0.10 & 0.30 & 0.11 & 0.32 \\
\hline & Primary & 0.31 & 0.46 & 0.39 & 0.49 & 0.37 & 0.48 \\
\hline & Secondary & 0.41 & 0.49 & 0.39 & 0.49 & 0.41 & 0.49 \\
\hline & Tertiary & 0.19 & 0.39 & 0.13 & 0.33 & 0.11 & 0.31 \\
\hline \multicolumn{2}{|l|}{ Years in Italy } & 11.99 & 5.03 & 6.65 & 4.09 & 2.37 & 2.53 \\
\hline \multirow[t]{7}{*}{ Area of origin: } & Sub-Saharan Africa & 0.21 & 0.41 & 0.20 & 0.40 & 0.19 & 0.39 \\
\hline & East Asia & 0.07 & 0.25 & 0.07 & 0.26 & 0.03 & 0.17 \\
\hline & Eastern Europe \& Central Asia & 0.19 & 0.39 & 0.25 & 0.43 & 0.32 & 0.47 \\
\hline & Latin America & 0.12 & 0.33 & 0.13 & 0.34 & 0.20 & 0.40 \\
\hline & Middle East \& North Africa & 0.30 & 0.46 & 0.24 & 0.42 & 0.20 & 0.40 \\
\hline & South Asia & 0.11 & 0.31 & 0.11 & 0.31 & 0.06 & 0.24 \\
\hline & & \multicolumn{6}{|c|}{ Labour market outcomes } \\
\hline \multicolumn{2}{|l|}{ Employed } & 0.96 & 0.20 & 0.92 & 0.27 & 0.79 & 0.41 \\
\hline \multicolumn{2}{|c|}{ Monthly earnings (euro) } & $1,228.97$ & 636.31 & $1,008.60$ & 441.57 & 816.04 & $1,423.99$ \\
\hline \multicolumn{2}{|c|}{ Formal employment contract } & 0.94 & 0.23 & 0.90 & 0.29 & 0.15 & 0.36 \\
\hline \multicolumn{2}{|c|}{ Occupation: ISEI $<30$} & 0.52 & 0.50 & 0.64 & 0.48 & 0.72 & 0.45 \\
\hline \multicolumn{2}{|c|}{ Occupation: SIOPS $<30$} & 0.64 & 0.48 & 0.78 & 0.42 & 0.81 & 0.39 \\
\hline \multicolumn{2}{|c|}{ Observations $(49,922)$} & \multicolumn{2}{|c|}{10,720} & \multicolumn{2}{|c|}{30,388} & \multicolumn{2}{|c|}{8,814} \\
\hline
\end{tabular}

Notes: The table reports means and standard deviations of selected characteristics of immigrants by residence status. ISMU surveys: 2001-2007. 
Table 2: Undocumented immigrants, temporary residents and permanent residents: employment and monthly earnings

\begin{tabular}{|c|c|c|c|c|c|c|c|c|}
\hline & \multicolumn{4}{|c|}{ Employed } & \multicolumn{4}{|c|}{ Log monthly earnings } \\
\hline & 1 & 2 & 3 & 4 & 5 & 6 & 7 & 8 \\
\hline & & $\mathbf{y s m} \leq 10$ & & all & & $\mathbf{y s m} \leq 10$ & & all \\
\hline \multirow[t]{2}{*}{ Temporary $\left(\alpha_{1}\right)$} & $-0.016^{* * *}$ & $0.026^{* * *}$ & $0.019^{* * *}$ & 0.003 & $-0.079 * * *$ & $-0.028^{* * *}$ & $-0.028^{* * *}$ & $-0.058^{* * *}$ \\
\hline & {$[0.004]$} & {$[0.004]$} & {$[0.004]$} & {$[0.003]$} & {$[0.008]$} & {$[0.007]$} & {$[0.008]$} & {$[0.006]$} \\
\hline \multirow[t]{2}{*}{ Undocumented $\left(\alpha_{2}\right)$} & $-0.133^{* * *}$ & $-0.029^{* * *}$ & $-0.042^{* * *}$ & $-0.091^{* * *}$ & $-0.319^{* * *}$ & $-0.175^{* * *}$ & $-0.181^{* * *}$ & $-0.233^{* * *}$ \\
\hline & {$[0.006]$} & {$[0.007]$} & {$[0.007]$} & {$[0.006]$} & {$[0.010]$} & {$[0.010]$} & {$[0.010]$} & {$[0.009]$} \\
\hline Baseline controls & $\mathrm{X}$ & $\mathrm{X}$ & $\mathrm{X}$ & $\mathrm{X}$ & $\mathrm{X}$ & $\mathrm{X}$ & $\mathrm{X}$ & $\mathrm{X}$ \\
\hline Individual controls & & $\mathrm{X}$ & $\mathrm{X}$ & $\mathrm{X}$ & & $\mathrm{X}$ & $\mathrm{X}$ & $\mathrm{X}$ \\
\hline Country of origin & & & $\mathrm{X}$ & $\mathrm{X}$ & & & $\mathrm{X}$ & $\mathrm{X}$ \\
\hline Observations & 38,594 & 38,594 & 38,594 & 49,922 & 30,558 & 30,558 & 30,558 & 39,745 \\
\hline R-squared & 0.043 & 0.071 & 0.088 & 0.078 & 0.090 & 0.204 & 0.227 & 0.254 \\
\hline \multicolumn{9}{|l|}{ Test: $\alpha_{1}=\alpha_{2}$} \\
\hline F-stat & 611.9 & 106.7 & 136.8 & 370.2 & 1279 & 421.0 & 470.5 & 668.2 \\
\hline p-value & 0.00 & 0.00 & 0.00 & 0.00 & 0.00 & 0.00 & 0.00 & 0.00 \\
\hline
\end{tabular}

Notes: The table reports Linear Probability Model (columns 1-4) and OLS (columns 5-8) estimates of labor market outcomes (probability of being employed in columns 1-4; log monthly earnings in columns 58) on dummies for residence status and other controls. The "Temporary" and "Undocumented" dummies identify immigrants, respectively, with temporary residence status and without legal status. Immigrants with permanent residence status are the benchmark group. "Baseline controls" include year dummies (2001-2007) and 11 province of residence dummies; "Individual controls" include gender, age, age squared, education dummies, years since arrival in Italy; "Country of origin" include a full set of 151 country dummies. In columns 1-3 and 5-7 we restrict the sample to immigrants with at most ten years of residence in Italy, while the unrestricted sample is used in columns 4 and 8.

ISMU survey years: 2001-2007. Heteroscedasticity-robust standard errors in parentheses: *** $p<0.01$, ** $p<0.05, * p<0.1$ 


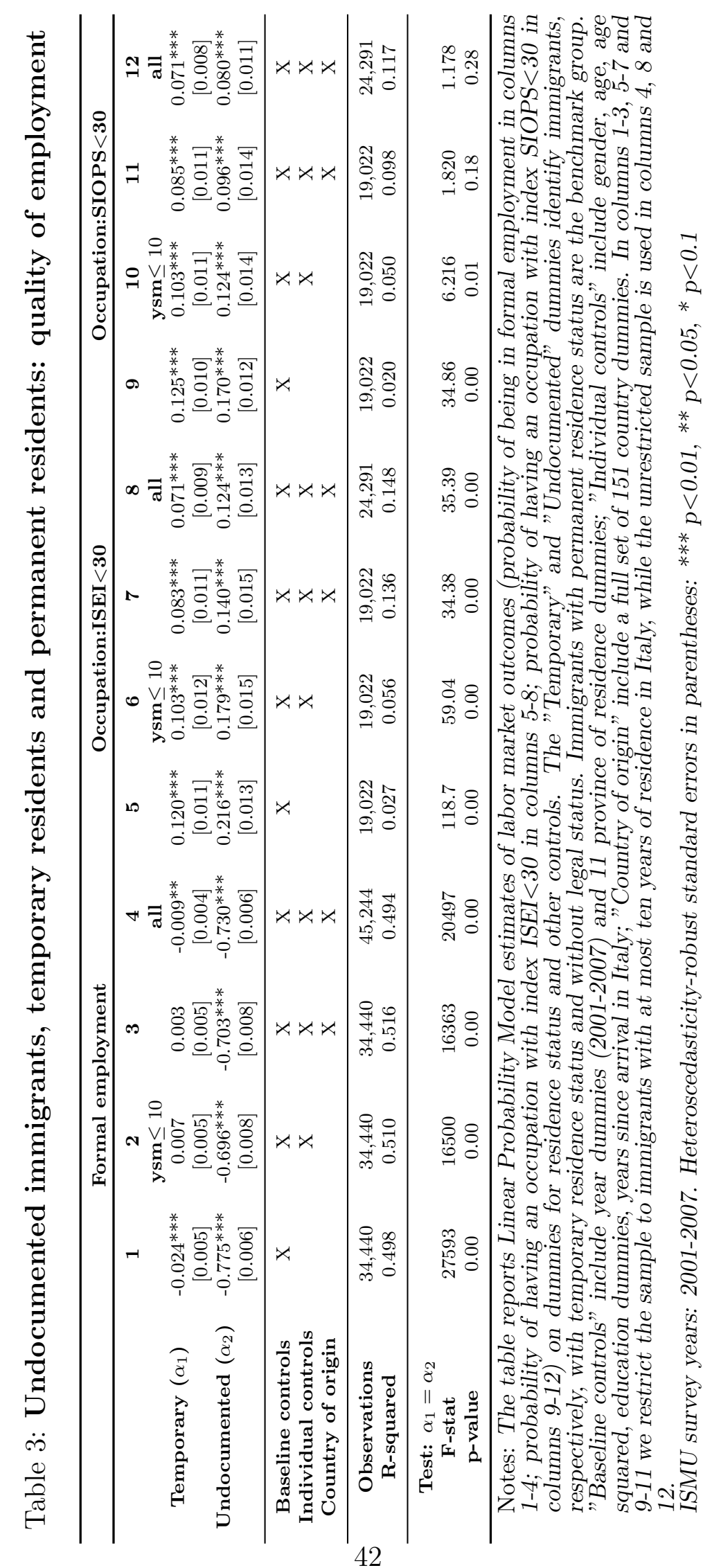




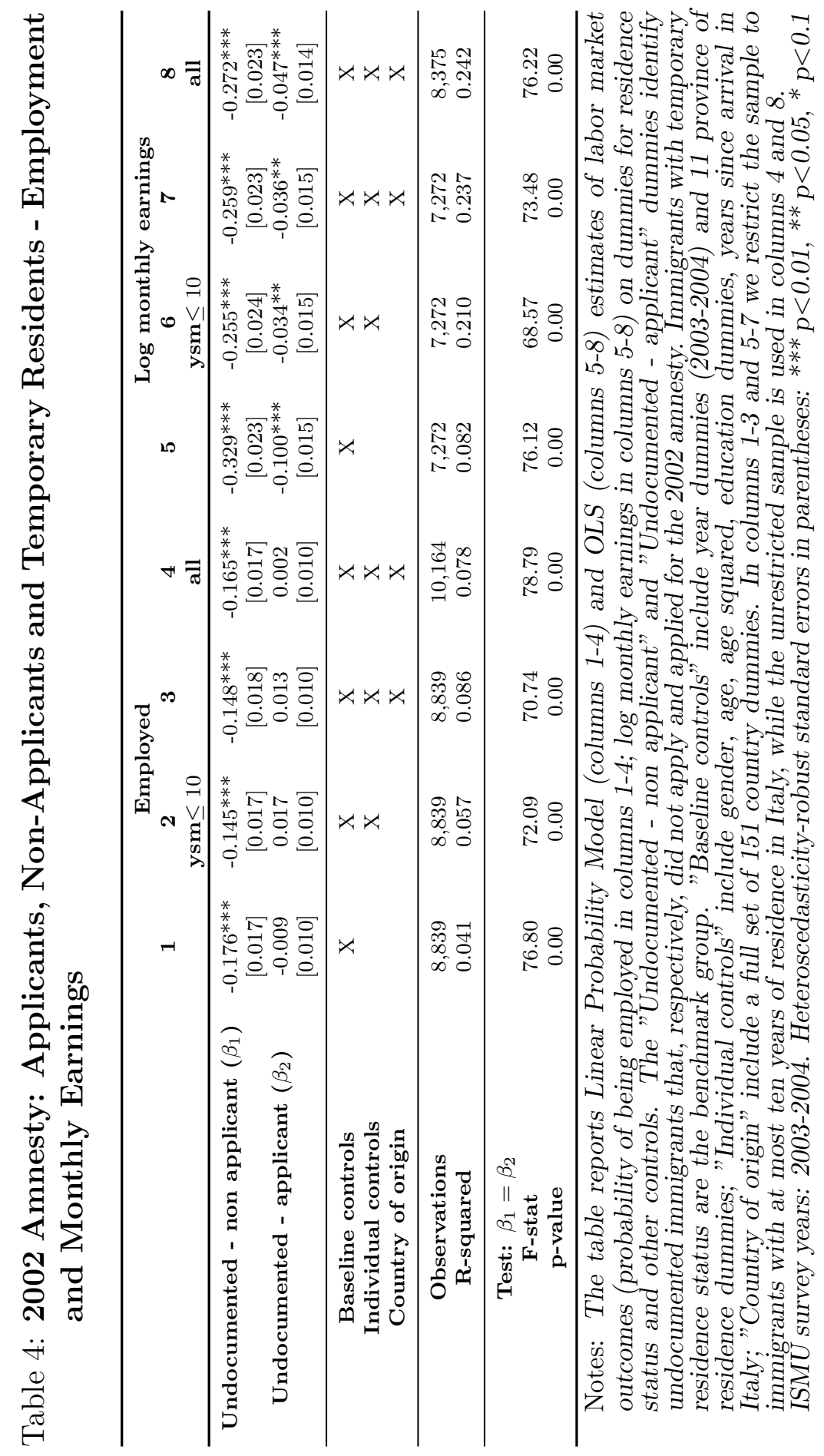




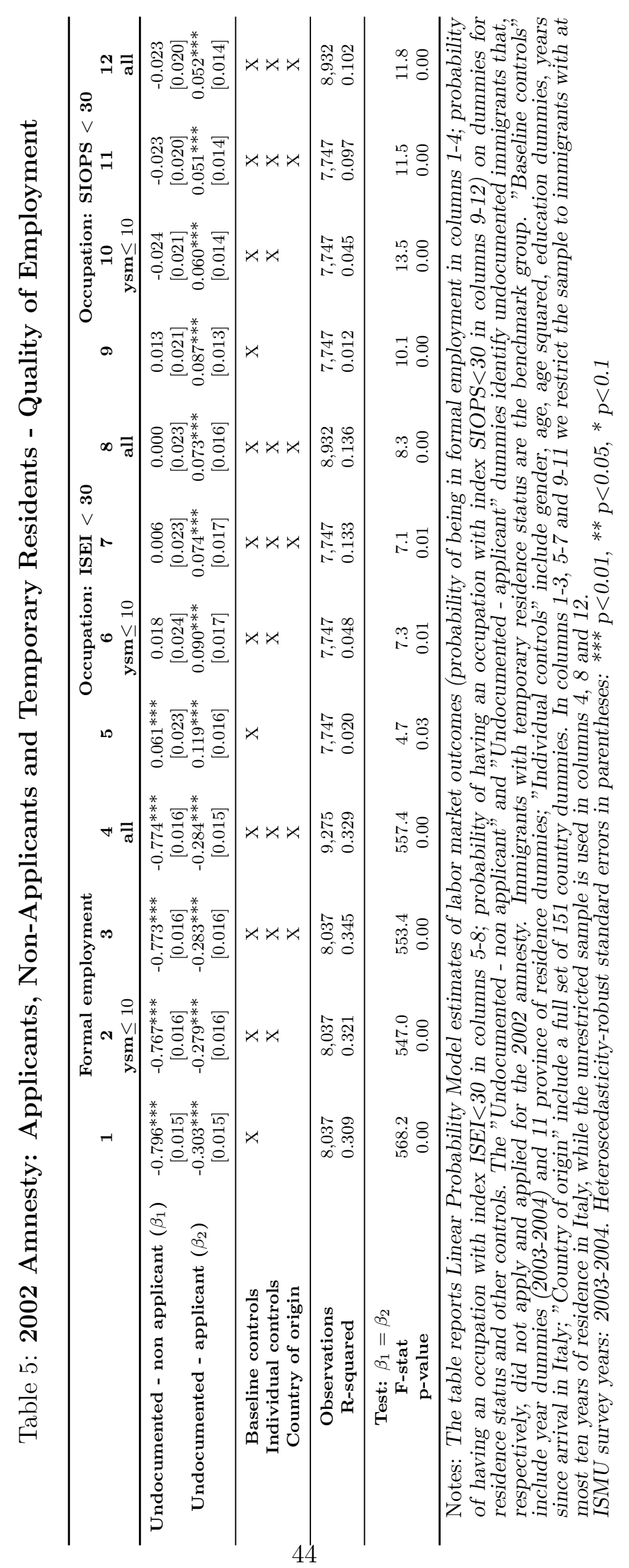




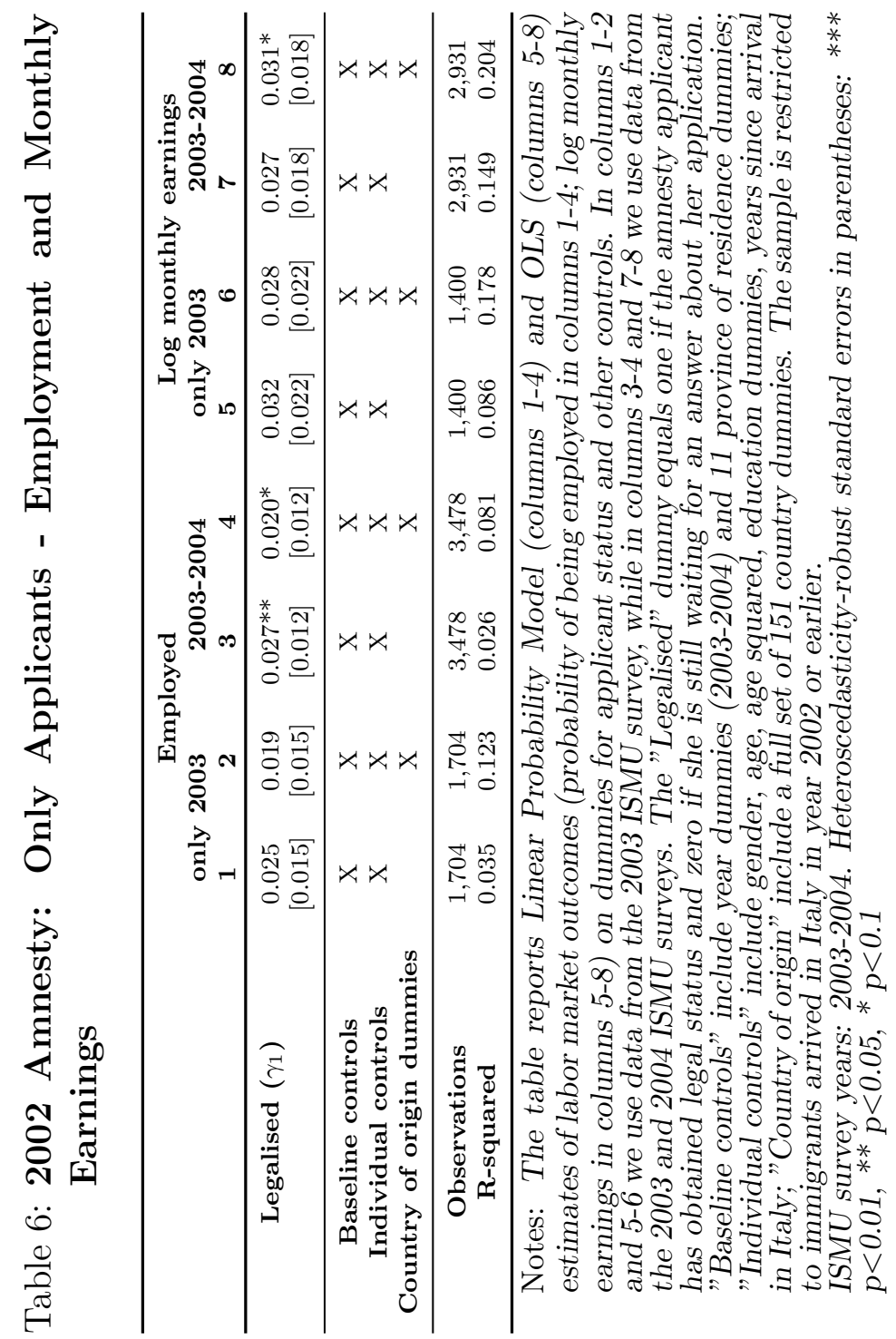




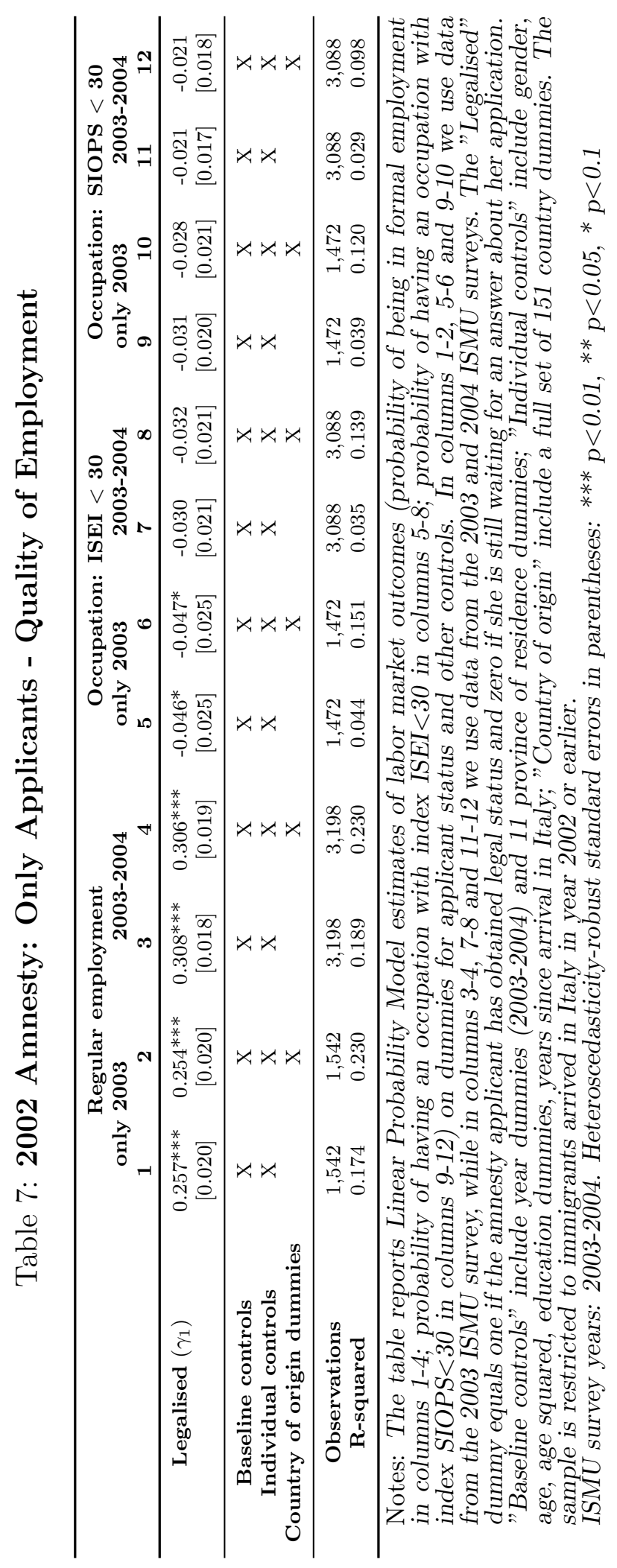




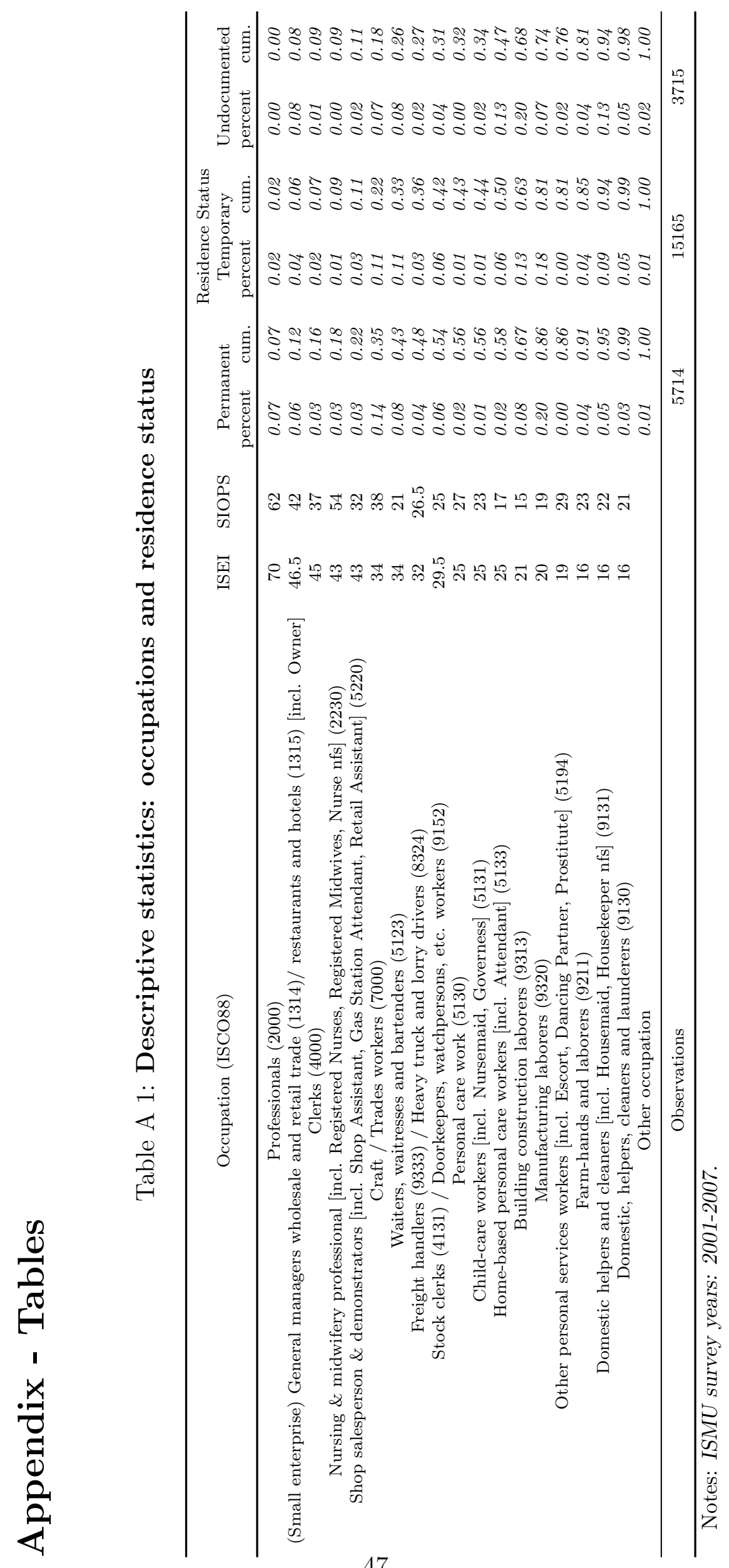




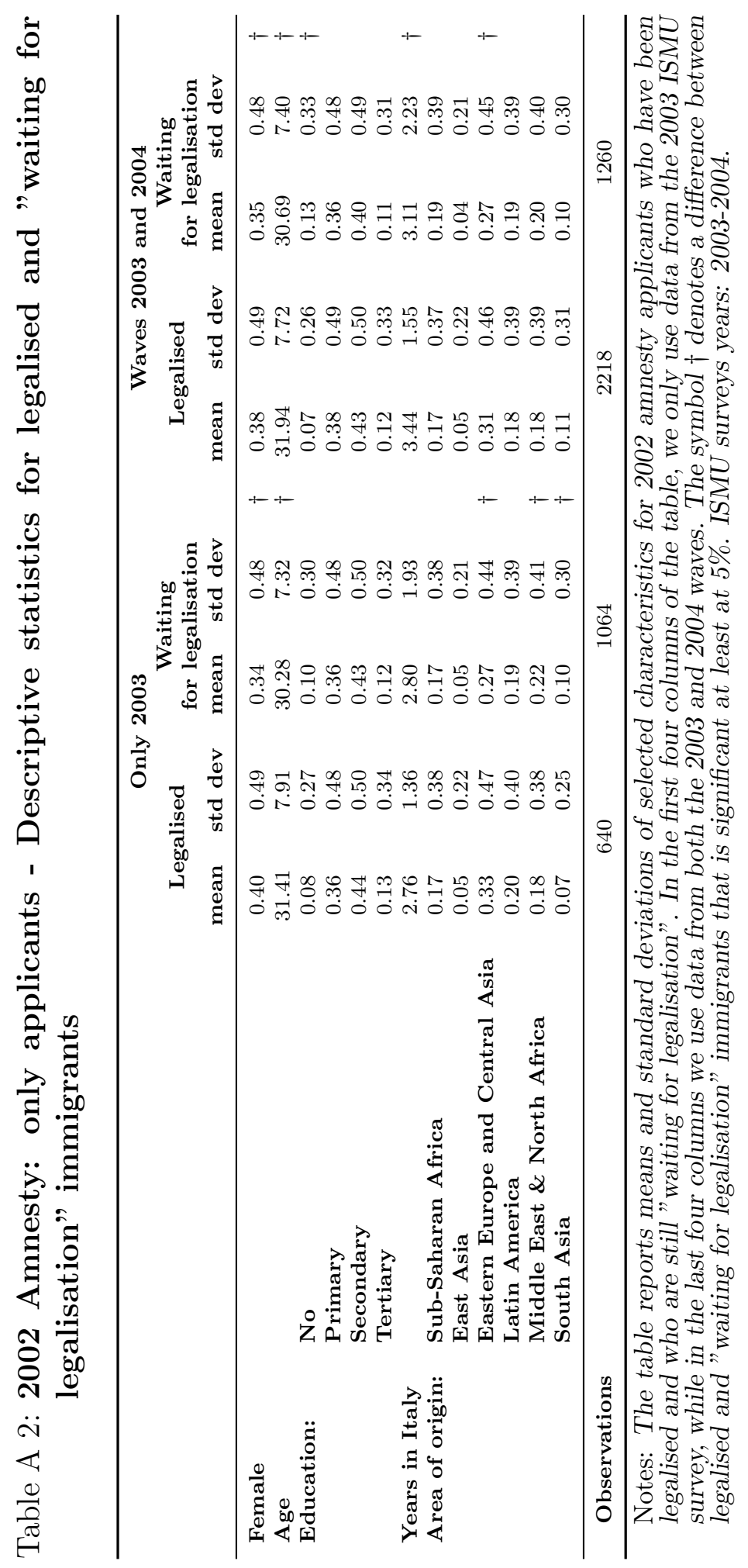

